\title{
Children With Autism Illuminate the Role of Social Intention in Word Learning
}

\author{
Julia Parish-Morris \\ Temple University \\ Kathy Hirsh-Pasek \\ Temple University
}

\author{
Elizabeth A. Hennon \\ University of Evansville \\ Roberta Michnick Golinkoff \\ University of Delaware
}

\author{
Helen Tager-Flusberg \\ Boston University School of Medicine
}

\begin{abstract}
To what extent do children with autism (AD) versus typically developing children (TD) rely on attentional and intentional cues to learn words? Four experiments compared $17 \mathrm{AD}$ children $(M$ age $=5.08$ years $)$ with 17 language- and 17 mental-age-matched TD children ( $M$ ages $=2.57$ and 3.12 years, respectively) on nonverbal enactment and word-learning tasks. Results revealed variability in all groups, but particularly within the AD group. Performance on intention tasks was the most powerful predictor of vocabulary in the AD group but not in the TD groups. These findings suggest that word learning cannot be explained exclusively by either attentional or intentional processes, and they provide evidence of a special role for intentional understanding in the vocabulary development of AD children.
\end{abstract}

Children acquire vocabulary at an impressive pace (Carey, 1978), and they acquire it primarily in the context of social interaction with other human beings (Hoff, 2003; Hoff \& Tian, 2005; Opie, Steele, \& Ward, 2004; Rowe, 2004; Tomasello, 1999; but see Chen \& Peng, 1995). Hotly debated, however, is the exact function that social interaction plays for children learning to map words onto referents. Does social interaction offer perceptual cues that direct attention to word referents? Or does it provide a gateway to a speaker's communicative intent, thus focusing listeners on the object or action that the speaker had in mind? Might there be a developmental progression with children first attending to the perceptual, attentional elements of social interaction and only later to the intentional cues to word reference? It has been difficult to distinguish empirically among these accounts. A comparison of the way typically developing (TD) and autistic (AD) children learn words offers

This research was completed as a dissertation by the second author. It was supported by National Science Foundation Grant SBR9601306 to Roberta Michnick Golinkoff and Kathy Hirsh-Pasek, by National Institute of Child Health and Human Development (NICHD) Grant HD25455-07 to Kathy Hirsh-Pasek, and Grant U19 DC 03610 to Helen Tager-Flusberg. We thank Shelly Ronen for her assistance.

Correspondence concerning this article should be addressed to Julia Parish-Morris, Department of Psychology, Weiss Hall, 1701 North 13th Street, Philadelphia, PA 19122-6085. Electronic mail may be sent to jparish@temple.edu. a window onto the role that social information plays in word learning. It has been argued that AD children pay less attention to social intentional cues than do TD children (Baron-Cohen, 1995). If true, and AD children nonetheless learn words in a manner similar to TD children, then understanding social intent might not be necessary for word learning. Furthermore, as AD children are somewhat heterogenous in their ability to access intentional cues, studying them offers a second way to examine the relative import of attentional and intentional social cues in vocabulary acquisition.

There are a plethora of theories that have been developed to account for patterns of early word learning. For example, there is the view that children's word learning is guided by a set of constraints that limit the number of hypotheses children need to make for what a word might mean (Booth, Waxman, \& Huang, 2005; Cimpian \& Markman, 2005; Merriman \& Evey, 2005). For the present purposes, however, we will consider only three types of theories: attentional, intentional, and hybrid. Attentional theories hold that social exchanges replete with movement, object handling, and gestures highlight certain objects and actions in the environment over others. Hearing a word in the presence of an interesting object that is the focus of a speaker's social cues can lead a child to

(C) 2007 by the Society for Research in Child Development, Inc. All rights reserved. 0009-3920/2007/7804-0015 
form a word-object association (Colunga \& Smith, 2005; McDuffie, Yoder, \& Stone, 2006; Plunkett, 1997; Regier \& Carlson, 2002 ; Samuelson \& Smith, 1998; Smith, 1995, 2000; Woodward \& Hoyne, 1999; Yoshida \& Smith, 2005). Based on this view, social beings may be no more important than any other exciting physical part of the environment (Smith, 2000). In fact, compelling evidence suggests that some word learning can progress via perceptual salience and general associative mechanisms (Kruschke, 2003; Pruden, Hirsh-Pasek, Golinkoff, \& Hennon, 2006). Children note word-object associations and track statistical regularities leading them to deduce the meanings of individual words and enabling them to construct mechanisms (e.g., the shape bias) that further aid the learning process (Cottrell \& Plunkett, 2002; Houston-Price, Plunkett, \& Harris, 2005; Regier \& Carlson, 2002; Samuelson \& Smith, 2005; Takata \& Nishikiori, 2005; Tan \& Schafer, 2005).

In contrast to attentional theories, intentional accounts of word learning suggest that social interaction enables children to access the intentions of people around them (Adamson, Bakeman, \& Deckner, 2004; Bloom \& Tinker, 2001; Diesendruck \& Bloom, 2003; Diesendruck, Markson, \& Akhtar, 2004). According to Tomasello (1999), "Sounds become language for young children when and only when they understand that the adult is making that sound with the intention that they attend to something" (p. 101). Considerable data have amassed to support this view. Studies by Baldwin, Tomasello, and their colleagues suggest that children engage in joint attention and recognize intentions by 18 to 24 months of age (for a review, see Akhtar \& Tomasello, 2000; Hollich, Hirsh-Pasek, \& Golinkoff, 2000; Poulin-Dubois \& Forbes, 2006).

In the past 10 years, midline or hybrid theories of word learning suggest that both attentional and intentional cues are critical to word learning and that the relative importance of these cues changes over the course of development (Akhtar, 2005; Hirsh-Pasek, Golinkoff, Hennon, \& Maguire, 2004; Hollich et al., 2000; Moore, Angelopolous, \& Bennet, 1999; Pruden et al., 2006). These theories claim that determining a speaker's intention is beneficial to the word-learning process (Akhtar, 2005; Hirsh-Pasek, et al., 2004; Hollich et al., 2000; Woodward, 2000), but it is not necessary for word learning to take place. In one hybrid theory, the emergentist coalition model (Hollich et al., 2000; see also Golinkoff \& Hirsh-Pasek, 2006), perceptual salience is the driving force behind children's first words (Plunkett, 1997; Samuelson \& Smith, 1998; Smith, 1995, 2000; Woodward \& Hoyne, 1999), but it is augmented by an evolving understanding of speaker intentions. Hirsh-Pasek, Golinkoff, and colleagues found evidence of a progression from purely attentional- to more intentional-based word learning between 10 and 24 months in TD children (Hollich et al., 2000; Pruden et al., 2006).

Historically, the relative contributions of attention and intention to language development have been difficult to delineate. Although many past studies of TD children have competently examined the roles of attention and intention in word learning, whether those studies were able truly to separate the two is unclear. TD children can access both kinds of information regardless of the paradigm. That is, although past experiments might have forced TD children to weight one type of cue over another, access to both types of cues was not eliminated. Even if a study was designed to measure the effect of only attentional cues or only intentional cues, TD children could still mine both types of information. For example, the social cues to speaker intent (e.g., looking, pointing, touching) are the same behaviors that attract children's attention. This makes it very difficult to determine whether attentional or intentional cues drive TD children's word learning.

One way to address this confound is to examine word learning in a population in which attention and intention might be disentangled. AD children have relatively more difficulty reading social intentional cues than do TD children (Baron-Cohen, 1995), although the majority of $\mathrm{AD}$ children nonetheless acquire some vocabulary (Baron-Cohen, Baldwin, \& Crowson, 1997; Bregman, 2005; Downs \& Smith, 2004; Heerey, Capps, \& Keltner, 2005; Preissler \& Carey, 2005; Ruffman, Garnham, \& Rideout, 2001; Zwaigenbaum et al., 2005). By comparing TD with AD children, we can begin to investigate the relative contributions of attentional and intentional cues to word learning. Furthermore, because of the variability in $\mathrm{AD}$ children's language skills, it is also possible to correlate language ability with intentional understanding.

Autism is a neurodevelopmental disorder that affects approximately 1 out of 150 (mostly male) children (Yeargin-Allsopp, Rice, \& Karapurkar, 2003; Rice et al., 2007a, 2007b; Yeargin-Allsopp, Rice, Karapurkar, Doernberg, et al., 2003). Although characterized by heterogeneity, two key features of the autism diagnosis are failure to develop normal language and impairment in social interaction (American Psychiatric Association [APA], 1994; Ghaziuddin \& Mountain-Kimchi, 2004; Zwaigenbaum et al., 2005). $\mathrm{AD}$ children often experience deficits in joint attention (Dube, MacDonald, \& Mansfield, 2004; Mundy, 2003; Warreyn, Roeyers, \& De Groote, 2003) and may have specific impairments in eye-gaze tracking (Grice 
et al., 2005; Senju, Tojo, \& Yaguchi, 2005; Senju, Yaguchi, \& Tojo, 2003; but see Kylliäinen \& Hietanen, 2004; Okada, Sato, \& Murai, 2004). Despite these difficulties, and the use of impaired language to diagnose autism, some AD children remain nonverbal and others possess remarkable language (especially vocabulary) skills relative to their intellectual level (Tager-Flusberg, 2006). Although many studies of $\mathrm{AD}$ children have focused on higher functioning individuals (Jarrold, Boucher, \& Russell, 1997; Kjelgaard \& Tager-Flusberg, 2001; Wire, 2005), the extant research on low-functioning AD children suggests that they are also capable of acquiring some vocabulary, especially nouns (Chan, Cheung, Leung, Cheung, \& Cheung, 2005; Charman et al., 2003; McDuffie, Yoder, \& Stone, 2005; Preissler \& Carey, 2005).

In the past, $\mathrm{AD}$ children were thought to be virtually incapable of understanding any social information (Rutter, 1978, but see Aldridge, Stone, Sweeney, \& Bower, 2000). Recent evidence, however, suggests that $\mathrm{AD}$ children may notice visibly obvious social cues that are based in perception and attention, such as the salient act of pointing (Bayliss \& Tipper, 2005; McDuffie et al., 2005). However, social impairment is still found when AD children are required to go beyond visible surface information and access the less visible intentions of a speaker (Baron-Cohen, 1995; Bloom, 2000; Preissler \& Carey, 2005; Warreyn, Roeyers, \& Oelbrandt, 2005). Considering the wellestablished link between the social and language arenas, the interesting array of abilities in AD children makes them a rich population for testing theories of word learning (Carpenter, Pennington, \& Rogers, 2001; McDuffie et al., 2005; Preissler \& Carey, 2005). If $\mathrm{AD}$ children have better access to social attentional cues than to social intentional cues, and if they can learn words in a controlled task, then social intent might be less necessary for word learning. Furthermore, if AD children with more intentional understanding learn words better than those with less intentional understanding, it becomes possible to sort out the relative contributions of attentional and intentional social information to word acquisition.

This research was designed to probe the capabilities of AD and TD children to recognize and respond appropriately to social attentional and social intentional cues. TD children were matched to AD children on either mental abilities or language skills. They participated in four tasks: two attentional and two intentional. Experiment 1 tested children on the ability to use social information to look at an object designated by an experimenter, using only attentional social information (e.g., eye gaze and vague verbal interjections). Experiment 2 tested whether children could learn a word through attentional means alone. Experiment 3 required that children be able to determine the experimenter's intention to perform a given action. Experiment 4 tapped children's understanding of speaker intent, requiring them to determine the referent for a novel word. AD children should perform as well as TD children on the attentional tasks (Experiments 1 and 2) but less well than TD children on social intentional tasks (Experiments 3 and 4). Finally, consistent with language, autism, and theoryof-mind research reporting links between social understanding and language ability (Hale \& TagerFlusberg, 2003, 2005a, 2005b; Shatz, 1994; Steele, Joseph, \& Tager-Flusberg, 2003; Tager-Flusberg \& Sullivan, 1994) we tested whether within-subject variation in task performance in the $\mathrm{AD}$ group (particularly on the tasks that require intentional understanding) related to language skill in a meaningful way. Specifically, we tested whether AD children use an understanding of other's intentions to access a richer vocabulary. Alpha was set at .05 for the current article and all significant results are $p<.05$ or better.

\section{General Methodological Overview}

\section{Participants}

AD children. Participants were 38 AD children and 40 TD children with no known developmental problems. Twenty-one AD children were not included because of a failure to meet diagnostic criteria $(n=$ $14)$ or a failure to complete all of the tasks $(n=7)$. Children were originally selected based on parental report of an autism diagnosis. During the first session, parents signed a release of confidential information form that was mailed to the child's clinician along with a request for the child's diagnostic report. Only children diagnosed with autism accompanied by documented evidence that they met Diagnostic and Statistical Manual of Mental Disorders (4th ed.; DSMIV) criteria were included in the sample (APA, 1994). It is important to note that only children diagnosed with autism were included in the study and children with autistic spectrum disorders were not. The final $\mathrm{AD}$ group consisted of 17 children (12 males, 5 females). One AD participant was Asian American and the rest of the participants were Caucasian.

The AD group had a mean age of 5.08 years (range $=36$ to 95 months). For purposes of matching control groups, each AD child completed the Peabody Picture Vocabulary Test, 3rd ed. (PPVT; Dunn \& Dunn, 1997) and the Differential Abilities Scales (DAS; Elliott, 1990). The AD group included a range 
of functioning levels. The mean PPVT raw score for the group was 23.12, which is an average age equivalence of 21 months. Their mean DAS nonverbal standard score was 76.06 , or an average age equivalence of 3.99 years (Table 1 gives means for all groups tested).

TD children. Forty TD children were recruited to serve as matched controls for the AD group. Each was matched individually to an AD child on gender. One TD group, the mental age (MA) group, was matched on nonverbal intelligence using the DAS (Burack, Iarocci, Flanagan, \& Bowler, 2004; Charman, 2004). Another TD group, the language age (LA) group, was matched on receptive vocabulary using the PPVT. Six control children were not used because of fussiness $(n=2)$, not matching any child from the AD group $(n=3)$, and the presence of a developmental disability $(n=1)$. Both control groups were significantly younger than the AD group. All children (AD, LA, and MA groups) came from middle- or upper-class homes in the greater Philadelphia area, and all parents of all children had at least a bachelor's degree.

$L A$ children. LA children $(M$ age $=2.57$ years, range $=17$ to 57 months) had a mean PPVT score of 24.06, or an average performance level of a 22-monthold. PPVT scores were not different from the AD group. Seven members of the LA group were less than 30 months of age (the minimum age for the DAS) and were tested on the lower preschool core subtests. Ten LA children were 30 months or older and were tested on either the lower or the upper preschool core and had an average DAS nonverbal standard score of
113.10. It was not possible to calculate a standard score for the 7 youngest children. However, their scores were included in estimates of age-equivalency levels (based on raw scores) and for group comparisons with the AD group. The overall LA group had an average nonverbal MA of 3.26 years, not different from the AD group. The final LA group consisted of 17 children (12 males, 5 females). All participants in the LA group were Caucasian.

$M A$ children. MA children ( $M$ age $=3.12$ years, range $=26$ to 59 months) had an average DAS nonverbal standard score of 116.07. The overall MA group had an average nonverbal MA of 4.02 years, not different from that of the AD group. Their mean PPVT score was 45.35 , or an average performance level of a 43-month-old. PPVT scores differed from those of the AD group. Two children were younger than 30 months, and the same procedures were followed as in the LA group. Fifteen children in the MA group were 30 months or older and were tested on either the lower or the upper preschool core, depending on age. The final MA group consisted of 17 children (12 males, 5 females). All participants in the MA group were Caucasian.

\section{Assessments}

$D A S$. The DAS is a battery of cognitive and achievement tests designed to assess the verbal and nonverbal abilities of children ranging from 2 years 6 months to 17 years 11 months. Internal and external validity and reliability have been well established for

Table 1

Demographic Information by Group

\begin{tabular}{lccc}
\hline & $\begin{array}{c}\text { AD group } \\
M(S D)\end{array}$ & $\begin{array}{c}\text { LA group } \\
M(S D)\end{array}$ & $\begin{array}{c}\text { MA group } \\
M(S D)\end{array}$ \\
\hline $\begin{array}{l}\text { Chronological age in years } \\
\text { Time in therapy }\end{array}$ & $5.07(1.25)$ & $2.57(0.90)$ & $3.12(0.81)$ \\
$\quad$ Duration in months & $30.1(15.1)$ & $0.00(0.00)$ & $0.00(0.00)$ \\
$\quad$ Hours per week & $30.2(10.9)$ & $0.00(0.00)$ & $0.00(0.00)$ \\
PPVT scores & & & $45.35(16.77)$ \\
$\quad$ Raw score & $23.12(20.57)$ & $92.06(21.32)$ & $107.13(7.07)$ \\
$\quad$ Standard score & $62.82(21.94)$ & 22 months & 43 months \\
$\quad$ Age equivalent & 21 months & $113.10(11.70)^{\mathrm{b}}$ & $116.07(16.59)^{\mathrm{c}}$ \\
DAS scores for the nonverbal cluster & & $3.11(1.38)$ & $4.02(1.29)$ \\
$\quad$ Standard score & & \\
$\quad$ Nonverbal mental age & $3.99(1.33)$ & & \\
\hline
\end{tabular}

Note. $\mathrm{AD}=$ autism; $\mathrm{LA}=$ language age; $\mathrm{MA}=$ mental age; PPVT = Peabody Picture Vocabulary Test; DAS = Differential Abilities Scales. ${ }^{a}$ The lower preschool score was based on the block building and picture similarities subtests. For the upper preschool score, the nonverbal cluster included the picture similarities, pattern construction, and copying subtests (Elliott, 1990).

beven children were too young (i.e., less than 30 months old) to calculate standard scores. Means and standard deviations are based on the remaining 10 children.

${ }^{\mathrm{c}}$ Two children were too young for standard scores; means and standard deviations reflect the performance of the remaining 15 children. 
the overall DAS as well as for both the lower and upper preschool cores (Elliott, 1990; Gordon \& Elliott, 2001). Although serious concerns have been raised about the appropriateness of matching AD children with TD children of comparable mental ability because of the extreme heterogeneity of the AD population (TagerFlusberg, 2004), we chose this scale as it is often used for populations with low verbal ability (Helfant, 2005; Walenta \& McCabe, 2004; Williamson, 2005).

$P P V T$. A receptive vocabulary test for all levels of language development, the PPVT has been normed for use with the age groups studied here (Dunn \& Dunn, 1997). It probes a wide variety of names for objects, actions, and events. Internal and external validity and reliability have been firmly established. Although the PPVT appears to be a good choice for the current study (because receptive word learning is of interest), concerns regarding picture vocabulary tests for AD children have been raised. Most worrisome is that such tests tend to overestimate the language abilities of AD children because many are adept at labeling objects (Shaked \& Yirmiya, 2004). Thus, the receptive language of TD children may be more advanced than $\mathrm{AD}$ children despite comparable PPVT scores. However, as the focus of the experimental tasks was on labeling skills, the decision was made to use the PPVT as opposed to matching based on a coalition of measures (Charman, 2004) or matching to a group with specific language impairment (TagerFlusberg, 2004).

\section{Stimulus Materials}

A variety of familiar and novel objects were used across the four tasks. Familiar objects (e.g., a children's picture book, a toy telephone) were chosen based on words commonly found in very young children's vocabularies (Fenson et al., 1994). Examples of novel objects included kitchen utensils (e.g., a safety latch used to hold cupboard doors closed), office devices (e.g., flat staple remover), or lab-created objects (e.g., carved wooden shapes). The objects were safe to play with, distinct in appearance, and had names that are not typically known by children of this age (Fenson et al., 1994). Parental report suggested that even the oldest children did not have a name (either expressive or receptive) for the objects and children themselves frequently asked, "What's this?" when provided with the objects.

\section{Design and Procedure}

Families were recruited through a brief article in the local newspaper and a letter. They were invited to participate with the following restrictions: For the $\mathrm{AD}$ group, the child had to be between 3 and 7 years of age and diagnosed with autism; for the TD groups, the child must have no known developmental problems.

Children were tested at three locations by the second author. All TD children (40 children) and most of the AD group ( 26 children) came to the laboratory. Testing was spaced across two sessions ( $M$ time between sessions $=18.38$ days). During the first session, the experimenter administered either the PPVT or the DAS (the remaining test was administered on the 2nd day of testing). The experimenter then provided children with an "intermission object." This intermission object (e.g., teddy bear) was not a part of the study but rather entertained the child before and between tasks. The first testing session included, in order, Experiments 1, 2, and 4 (see the following sections for detailed descriptions of each task). For Experiments 2 and 4, only half of the task was administered on the 1st day. The design equated the number of new words that the child was required to learn per testing session (three). All sessions were videotaped to allow for reliability coding. In the second session, the experimenter administered either the DAS or the PPVT followed by Experiments 2, 3, and 4 (in order). For Experiments 2 and 4 , this was the remaining half of the full experiment.

\section{Experiment 1: Can Young Children Use Social Attention to Guide Object Selection?}

The task in Experiment 1 did not involve word learning but merely required that children follow a speaker's attentional cues. Prior studies found that eye gaze was not an effective social cue for $A D$ children when used in isolation (Baron-Cohen et al., 1997; Leekham, Hunniset, \& Moore, 1998; Leekham, Lopez, \& Moore, 2000; Preissler \& Carey, 2005; Ristic, Mottron, \& Friesen, 2005). However, recent findings suggest that eye gaze should not be discarded as a possible attentional social cue; $\mathrm{AD}$ children do sometimes notice it (Kylliäinen \& Hietanen, 2004; Okada et al., 2004). Furthermore, Bayliss and Tipper (2005) found that AD children definitely notice pointing and handling. Thus, the current experiment combined perceptually obvious referential cues (pointing and touching with eye gaze, as well as the use of a few vague verbal interjections or a sentence) to direct AD children's attention to a specific object in a non-word-learning task. It was hypothesized that all $\mathrm{AD}$ and $\mathrm{TD}$ children would respond to these social cues in the absence of a novel word, directing their attention 
to the object indicated by the experimenter. The dependent variables were looking time and the direction of the first look.

\section{Method}

Participants. See the General Methodological Overview.

Procedure. Four objects were placed on a tray held on the experimenter's lap out of reach of the child. After calling their name to gain children's attention, the experimenter directed them to a target object by both looking at and either pointing to or touching the object. This was accompanied either by verbal interjections (e.g., "ooh," "aah") or with a sentence (e.g., "This is neat"). Each child participated in the four possible combinations of looking with either (a) touching or (b) pointing and (c) verbal interjections or (d) a sentence. On all occasions, the experimenter held the pose (e.g., looking at and touching the blocks with minimal language) for $5 \mathrm{~s}$ before handing the target object to the child. Children played with each toy for approximately $30 \mathrm{~s}$ after it was handed to them. Counterbalancing controlled for the position of target objects on the tray, the object indicated by each language-gesture combination, order of the objects, and order of the combinations.

Coding. Children's looking responses during the $5 \mathrm{~s}$ that the experimenter held her pose were coded offline from videotapes. Twenty-five percent of the tapes were recoded for intrajudge reliability $(M r=$ .99 , range $=.96$ to .99 ) and $10 \%$ of the tapes were recoded by a blind coder for interrater reliability $(M r=.98$, range $=.95$ to .99$)$.

\section{Results}

Data from two AD children were unusable (one for taping difficulties and one for low attention). The dependent measures were where the child first looked (e.g., target, experimenter, another object, elsewhere) during test and how long the child looked at each.

A multivariate analysis of variance (MANOVA) revealed no effects of gender or of how the target was indicated (pointing vs. touching and sentences vs. minimal language) on looking time or correct number of first looks. Data were collapsed across these variables. Group differences were found in the average amount of time spent looking at the target object, $F(2$, $46)=12.31$, partial $\eta^{2}=.35$, and in number of correct first looks, $F(2,46)=8.83$, partial $\eta^{2}=.28$ (see Table 2), but post hoc Scheffé tests revealed that all three groups succeeded at the task as predicted. The AD group looked significantly longer at the target, $t(14)=5.11$, and more frequently at the correct object first, $t(14)=7.75$, than predicted by chance (there were four objects; therefore, chance was defined as looking at each object $25 \%$ of the time and looking first at each object equally often).

The AD group differed from both the LA group and the MA group in looking time at the target, but the control groups did not differ from each other. Both control groups looked longer at the target object (Ms: $\mathrm{LA}=4.10 \mathrm{~s}, \mathrm{MA}=4.42 \mathrm{~s}$ ) than did the $\mathrm{AD}$ group $(M=2.95 \mathrm{~s})$. Similarly, the AD group differed from the LA and MA groups on proportion of correct first looks, but the LA and MA groups did not differ from each other. Thus, although group differences existed and the control groups outperformed the AD group (Ms: LA $=3.82$ times out of $4, \mathrm{MA}=3.94$ times, $\mathrm{AD}=3.07$ times), all groups succeeded in locating and attending to the target object.

\section{Discussion}

All children (AD and TD) responded appropriately to the available social information and directed their attention to the object indicated by the experimenter. This finding is interesting as it contrasts with findings from Baron-Cohen et al. (1997) and Preissler and Carey (2005). Although both of these studies concluded that AD children can not use social cues to direct attention, both relied solely on eye gaze as the main social cue of interest. Consistent with Bayliss and Tipper's (2005) findings, we found that AD children could respond to social cues, indicating a target object when the operational definition of social cue was broadened to include pointing, touching, vague verbal interjections, and occasionally a sentence. Given AD children's success in this task,

Table 2

Social Attention Without Word Learning: Children's Looking Responses on Experiment 1

\begin{tabular}{lccc}
\hline & $\begin{array}{c}\text { AD group } \\
M(S D)\end{array}$ & $\begin{array}{c}\text { LA group } \\
M(S D)\end{array}$ & $\begin{array}{c}\text { MA group } \\
M(S D)\end{array}$ \\
\hline $\begin{array}{l}\text { Total correct first } \\
\text { looks (out of 4) }\end{array}$ & $3.07(1.03)$ & $3.82(0.39)$ & $3.94(0.24)$ \\
Time looking at (out of 5 s): & & \\
$\quad$ Indicated object & $2.95(1.29)$ & $4.10(0.71)$ & $4.42(0.48)$ \\
$\quad$ Experimenter & $0.34(0.38)$ & $0.34(0.41)$ & $0.27(0.34)$ \\
$\quad$ Other object on tray & $0.50(0.62)$ & $0.27(0.41)$ & $0.11(0.22)$ \\
$\quad$ Not attending to task & $1.21(0.90)$ & $0.29(0.32)$ & $0.20(0.16)$ \\
\hline
\end{tabular}

Note. $\mathrm{AD}=$ autism; $\mathrm{LA}=$ language age; $\mathrm{MA}=$ mental age. 
the next question is whether they can marshal these attentional cues in the service of word learning.

\section{Experiment 2: Can Young Children Use Social Attention to Learn a Novel Word?}

Baron-Cohen et al. (1997) found that school-aged AD children could not follow a speaker's eye gaze to determine the correct referent for an object label. Was this due to an inability to use any social information, or did AD children have difficulty learning words because of issues with eye gaze? Experiment 2 asks whether children can use a richer set of social cues to guide word learning in a situation of overlapping cues and competing cues. This study differs from the study on early word learning by Preissler and Carey (2005) in which AD children demonstrated word learning without social cues. In their task, children saw one familiar and one novel object or picture, and were asked for a nonsense word (e.g., "Show me the blicket"). The authors suggested that AD children demonstrated the principle of mutual exclusivity (Markman, Wasow, \& Hansen, 2003) or N3C (the tendency to attach a novel name to an unnamed novel object; Golinkoff, Mervis, \& Hirsh-Pasek, 1994) by pairing the novel word with the novel object as opposed to the familiar, already-named object. Our task is much more stringent in that we presented the children with two novel objects and thus when social cues and perceptual cues are in conflict, the referent can only be determined by attending to social cues.

\section{Method}

Participants. See the General Methodological Overview.

Procedure. Experiment 2 was a modified replication of Hollich et al.'s (2000) Experiment 3 wherein children played with consecutive sets of two objects (two familiar objects or two novel objects, one boring and one interesting). As in Hollich et al., we verified that the objects were interesting (e.g., a plastic wand filled with liquid and sparkly moons and stars) or boring (e.g., a white plastic bottle opener) through the use of an initial salience trial. Children played with the objects for $30 \mathrm{~s}$ and indicated which one they "like better." The object chosen during salience was considered the interesting object for the remainder of the experiment with that participant.

As our study tested older children than Hollich et al. (2000), it required some modifications. First, rather than asking children to look at the target during test, the experimenter in our task asked the children to pick up the labeled object. Second, the total number of objects was doubled, from two pairs of novel objects to four pairs (and from two pairs of familiar objects to four pairs). Third, the experiment was split in half, with each child being tested with two pairs of objects (one familiar and one novel) on each day of testing.

The pattern of testing was as follows: (a) a familiar phase, in which children were asked to pick up a familiar object (e.g., book, shoe); (b) a salience phase, in which children were presented with both novel objects in a pair and asked to indicate which object they found interesting; (c) a training phase, in which the experimenter pointed at or touched either the interesting or the boring novel object and labeled it with a nonsense word (e.g., blicket); (d) a test phase, in which children were asked to pick up the novel object that was labeled by the experimenter (e.g., "Where's the blicket? Find the blicket!"); (e) a new-label phase, in which the child was asked to retrieve an object labeled by a new, previously unheard nonsense word (e.g., "Can you find the glorp?"); and (f) a recovery phase, in which the child was again asked to find the original labeled object (e.g., "Where's the blicket?"). Based on the principle of exclusivity (Markman et al., 2003) or N3C (Golinkoff et al., 1994), children should pick up the novel object that was not labeled during the training phase (Hollich et al., 2000; Preissler \& Carey, 2005).

These phases occurred in one of two conditions. In the coincidental condition, social attentional cues and object preference were in concert as the experimenter labeled the interesting object. In the conflict condition, the experimenter labeled the boring object; therefore, perceptual cues were in conflict with social attentional cues.

Given the decision to conduct this as a withinsubjects design, each child heard a label in four conditions: pointing or touching the novel object when it was interesting or boring. The order of condition (coincidental and conflict) and the methods of teaching (pointing or touching) were counterbalanced and randomized with respect to each other across children.

Coding. Coding was done on-line by noting whether the child chose (a) the labeled object, (b) the unlabeled object, (c) both objects, or (d) neither object. The object selected first was coded as the choice for the trial. All tapes were recoded to verify accuracy. Interrater reliability for coding found no discrepancies between coders $(r=1.0)$. 


\section{Results}

The dependent measure was the percentage of test trials where children selected the labeled object. However, the key was the pattern of results across three types of test trials (test-new-label - recovery). A quadratic pattern (or a V-shaped pattern) indicates that children learned the word rather than just selected one object or the other repeatedly (Hollich et al., 2000).

A repeated measures analysis of variance (ANOVA) comparing gender, testing session, type of social cue, object type (interesting or boring), and trial type (familiar vs. novel object set) found no effects of gender, testing session (Day 1 or 2), or social cue (pointing vs. touching). Data were collapsed across these variables. Preliminary analyses identified an effect of object type (interesting vs. boring), $t(50)=$ 3.61, and subsequent analyses were conducted separately for interesting and boring trials. Performance on the familiar trials indicated that all children were capable of performing the task. Across groups, children selected the correct familiar object a mean of 3.68 out of 4 trials (range $=2$ to 4 ; see Table 3 for group means).

Results with the interesting object. A repeated measures ANOVA tested for differences between the test, new-label, and recovery trials and for group effects. No main effect of group was found, $F(2,48)=1.33$. A planned contrast for trial demonstrated a quadratic pattern, such that all groups selected the labeled object more frequently on the test and recovery trials than on the new-label trial, $F(1,48)=90.99$, partial $\eta^{2}=.66$. That is, when the interesting object was labeled, both $\mathrm{AD}$ and TD children were able to attach the word to the interesting object correctly.

Results with the boring object. A repeated measures ANOVA tested for differences between the test, newlabel, and recovery trials and for group effects. Because a main effect of group was found, $F(2$, $48)=3.70$, partial $\eta^{2}=.13$, planned contrasts were conducted separately for each group. Both the LA group, $F(1,16)=11.52$, partial $\eta^{2}=.42$, and the MA group, $F(1,16)=34.89$, partial $\eta^{2}=.67$, demonstrated the V-shaped pattern with the boring object. In contrast, although there was a trend toward a quadratic form, scores from the AD group did not reach significance, $F(1,16)=1.92$, partial $\eta^{2}=.11$.

When the boring object was labeled, the AD group selected it $44 \%$ of the time in test trials, $29 \%$ of the time in new-label trials, and $53 \%$ of the time in recovery trials. Although this pattern failed to reach significance, it was V-shaped. Moreover, although the AD group did not choose the boring object more often
Table 3

Social Attention With Word Learning: Children's Performance in Experiment 2 by Group

\begin{tabular}{lccc}
\hline & $\begin{array}{c}\text { AD group } \\
M(S D)\end{array}$ & $\begin{array}{c}\text { LA group } \\
M(S D)\end{array}$ & $\begin{array}{c}\text { MA group } \\
M(S D)\end{array}$ \\
\hline Familiar trials & & \\
$\quad$ Correct choices & $3.41(0.62)$ & $3.69(0.60)$ & $3.94(0.24)$ \\
$\quad$ out of 4) & & \\
Proportion correct & $0.85(0.15)$ & $0.92(0.15)$ & $0.99(0.06)$ \\
Coincidental condition (proportion labeled object choices) \\
Salience trial & $1.00(0.00)$ & $1.00(0.00)$ & $1.00(0.00)$ \\
Test trial & $0.91(0.26)$ & $0.82(0.30)$ & $0.88(0.28)$ \\
New-label trial & $0.30(0.40)$ & $0.11(0.22)$ & $0.07(0.26)$ \\
Recovery trial & $0.89(0.35)$ & $0.79(0.36)$ & $0.94(0.29)$ \\
Conflict condition (proportion labeled object choices) & \\
Salience trial & $0.00(0.00)$ & $0.00(0.00)$ & $0.00(0.00)$ \\
Test trial & $0.44(0.43)$ & $0.68(0.39)$ & $0.85(0.29)$ \\
New-label trial & $0.29(0.31)$ & $0.21(0.31)$ & $0.09(0.26)$ \\
Recovery trial & $0.53(0.38)$ & $0.71(0.40)$ & $0.85(0.29)$ \\
Overall performance (proportion labeled object choices) \\
Salience trial & $0.50(0.50)$ & $0.50(0.50)$ & $0.50(0.50)$ \\
Test trial & $0.69(0.29)$ & $0.75(0.32)$ & $0.87(0.19)$ \\
New-label trial & $0.30(0.26)$ & $0.15(0.20)$ & $0.08(0.20)$ \\
Recovery trial & $0.71(0.27)$ & $0.75(0.33)$ & $0.90(0.16)$ \\
\hline
\end{tabular}

Note. $\mathrm{AD}=$ autism $; \mathrm{LA}=$ language age $\mathrm{MA}=$ mental age.

than would be predicted by chance in the test, newlabel, or recovery trials, they did choose the boring object significantly more often during test than they did during the salience trial, $t(16)=4.24$. Thus, although AD children (on average) did not learn the name for a boring object, there is strong evidence that the speaker's actions did succeed in drawing their attention to the boring toy.

\section{Discussion}

All children were fundamentally capable of performing the task, as demonstrated by the familiar trials. Furthermore, all children were capable of learning a novel word under some circumstances. Both the AD and the TD children succeeded in the familiar trials and when the interesting toy was labeled in the coincidental condition. However, when the boring object was the target (the conflict condition), AD children experienced greater difficulty and as a group did not reliably demonstrate word learning. TD children attached the label to the correct object even when the boring toy was the target.

Why did the AD children appear to have such difficulty learning a word for a boring object? Prior research with TD infants may shed light on the current results. Research has shown that 12-month-olds cannot 
easily learn a name for a boring object and cannot learn a word when objects are of equal salience unless the experimenter looks at the target object, picks it up, and slowly rotates it while providing the label (Hollich et al., 2000). Hollich et al. (2000) explained this finding by appealing to the emergentist coalition model, which posits that young word learners initially rely on perceptual salience and general associative mechanisms to attach words to referents. From this perspective, AD children appear to learn names for perceptually salient objects that they find interesting. Thus, they seem to harness social attentional and perceptual cues in the service of word learning.

Recently, Pruden et al. (2006) made a discovery that bears on the interpretation of these findings: Ten-month-old infants actually map a word onto the wrong referent when faced with conflicting social and perceptual cues! AD children in the present experiment did not attach a word to either the interesting or the boring object in the conflict condition. This suggests that whereas 10-month-olds are completely perceptually driven, AD children may attend to both social and perceptual cues. Performance on the interesting trials suggests that $\mathrm{AD}$ children can acquire words when all the available information is in alignment, that is, when social cues point to the same object that children find attractive, but cannot learn the name for an object when the social cues and perceptual cues conflict.

Alternatively, there may be a fundamental difference in the role social cues play when learning the name for an interesting versus a boring object. Perhaps social information is only confirmatory when a label is offered for interesting objects; that is, perhaps children use the speaker's actions simply as a means of double-checking that they are looking at the same object as the speaker. In contrast, for boring objects, children may need to (a) recognize that the speaker is indicating a different object than they would like to explore, (b) use that information to stop attending to the desired object, and (c) use social cues to locate the actual referent of the speaker's label. This process may involve more of the ability to combine complex social attentional information than young children or AD children possess (Hollich et al., 2000; Pruden et al., 2006).

Another possibility for AD children's failure to learn the label for a boring object might arise from a failure to discern the speaker's communicative intentions (Bloom, 2000; Tomasello, 1999) rather than from a problem with using attentional social information. In that case, $\mathrm{AD}$ children may have noticed the speaker's actions but could not interpret them to mean that the label was meant for the boring object.
Experiments 3 and 4 focus on the role of social intention in word learning.

\section{Experiment 3: Can Young Children Detect Social Intention in a Failed Imitation Task?}

The results of Experiments 1 and 2 suggest that $\mathrm{AD}$ children notice and respond to visible forms of social information in some contexts and learn a word when social and perceptual cues coincide. However, it was difficult for $\mathrm{AD}$ children to follow the attention of a speaker to learn the name for a boring object—a skill successfully demonstrated by TD 19- to 24-montholds (Hollich, et al., 2000). Perhaps the word-learning strategy adopted by TD toddlers involves at least some analysis of the intentions of the speaker. However, it is not clear whether the AD children's difficulty in the conflict condition of Experiment 2 was due to attentional processing demands of the wordlearning task or to a lack of intentional understanding. Experiment 3 addressed this question by testing whether AD children had difficulty understanding intentions in a non-word-learning task.

A behavioral re-enactment paradigm is a method used to determine whether children understand another's intentions (Meltzoff, 1995). Meltzoff (1995) found that 18- to 20-month-olds produced an adult model's intended action, without seeing the completed action, after the adult failed at a task. Children inferred what the adult meant to do and modeled their own behavior accordingly. Bellagamba and Tomasello (1999) found that 12-month-olds rarely produced the intended action in Meltzoff's paradigm, suggesting that the ability to "read" intention develops over time.

It has been argued that $\mathrm{AD}$ children have an impaired ability to read intentions (Baron-Cohen, 1995; Bloom, 2000; Charman, 2000; Charman et al., 1998; Griffin, 2002; Peterson, 2005; Rogers \& Pennington, 1991; Ruffman, 2000, Ruffman et al., 2001; Tager-Flusberg, 1999, 2001; Tomasello, 1999). However, these studies tested children's theory of mind, the understanding that others may have different thoughts, feelings, and beliefs from their own (Wellman, 1990). Although AD children may never develop a theory of mind (Baron-Cohen, 1995), recent evidence suggests that they may be capable of recognizing intentionality in others' actions (Aldridge et al., 2000; Carpenter et al., 2001; Hornbeck, 2001; Nadel, 2004).

We used a modified version of Meltzoff's (1995) paradigm. Given challenges to the objects and actions used in Meltzoff's original experiment (Carpenter \& 
Call, 2002; Carpenter et al., 2001; Charman et al., 1998; Charman \& Huang, 2002; Heyes, 2001; Huang, Heyes, \& Charman, 2002; Want \& Harris, 2002; Whiten, 2002), we changed the stimuli for the current experiment. The number of objects available at one time was changed by increasing the number of possible object combinations that could occur by chance. Moreover, objects and the actions performed with them were altered to form two sets: one in which the actions performed were canonical (e.g., using a mallet to hammer a peg through a peg board) and one in which the actions performed were noncanonical (e.g., stacking a block on top of a toy tree).

Meltzoff's (1995) results suggest that both control groups should succeed on this task given that they are substantially older than the 18- to 20-month-olds tested in the original experiment. Given Carpenter et al.'s (2001) findings as well as Aldridge et al.'s (2000) findings, AD children may succeed on this task, particularly with the canonical set. However, the abundance of evidence that AD children have difficulty understanding the thoughts of others (see Baron-Cohen, 1995) suggests that to the extent that this task requires children to discern the thoughts of another, the AD group might fail, especially in the noncanonical condition in which the experimenter's actions are not consistent with either children's previous experience with the toys or typical object affordances. An important difference between the present task and prior tasks (Aldridge et al., 2000; Carpenter et al., 2001) is that the objects in the noncanonical condition are real objects. Thus, the objects are (a) very familiar and (b) have very obvious typical affordances. Succeeding in this condition requires that children understand an experimenter's intention even though it violates their own assumptions about how these toys are used.

\section{Method}

Participants. See the General Methodological Overview.

Procedure. Two sets of four recognizable objects were used (e.g., blocks, trucks, trees). The canonical set consisted of several children's toys (a wooden pegboard with pegs, a wooden mallet, and a plastic post with stackable rings). For this set, the canonical actions performed with the toys by the experimenter conformed to the objects' affordances and typical uses (pegs are hammered into the pegboard with the wooden mallet, rings are stacked onto the plastic post). The noncanonical set also included familiar objects (a plastic watering can, a plastic palm tree, a toy truck, and a wooden block). However, non- canonical actions were chosen to violate the most common relationships between these objects (i.e., water the truck and stack the block on top of the tree). This allowed us to separate the objects' affordances and common usages from the actions demonstrated (Huang et al., 2002). This manipulation represents a marked departure from the dual affordance method used by Carpenter et al. (2001) and Aldridge et al. (2000), in which a single object could be manipulated in two ways (i.e., a hammer could be pulled apart or used to hammer a peg). Here the most common affordances of each object in the noncanonical set were purposefully violated, requiring that children infer intended actions that were potentially contradictory to their own prior experience with similar toys.

Another modification was made to Meltzoff's (1995) original experiment based on research suggesting that the language used by an adult influences whether children interpret actions as intentional (Carpenter, Akhtar, \& Tomasello, 1998; Wittek \& Behrend, 2002). To highlight the fact that the intended action was not completed and increase children's awareness that a mistake had occurred, the experimenter said, "Whoops! I missed it" or "Oh no! That's not right" immediately after her failed attempt. This change should make it more likely that children could interpret the speaker's intent as wanting to complete the action.

Two further changes were made. First, to encourage children to perform the experimenter's action (either by mimicking the demonstrated action or by producing the intended action), the experimenter gave the toys to the child while saying "Can you help me? Can you do it for me?" If the child discerned what the experimenter was trying to do, this request should increase instances of intended action performance. Second, we only used Meltzoff's (1995) intention condition, in which the adult failed to complete an action three times in three different ways. For example, when attempting to hammer the pegs, the adult would miss and hit the board to the right of the peg, then to the left, and then to the back of the peg. This suggested that the experimenter was not purposefully hitting one area but was actually failing at the task.

Children were tested in a within-subjects design, with canonical or noncanonical object sets received in a block. Children were tested with two different pairs of objects in the canonical set and with two different pairs of objects in the noncanonical set. First, the experimenter placed a set of four objects onto a tray, selected one pair of two objects, and attempted to perform an action with them (either). She failed to complete the intended action three times and expressed her dismay each time. She then picked up 
the second pair of objects from the set and again failed to perform a different attempted action three times, expressing her dismay each time. After the third attempt, the experimenter said, "Can you help me? Can you do it for me?" and slid the tray toward the child. The first action children performed with each pair of objects was coded. Next, the experimenter placed four objects from the second object set onto the tray, and the previously described sequence was repeated. The order of sets (canonical vs. noncanonical), the order of the pairs within a set, and the location of the objects on the tray were all counterbalanced.

Coding. Coding was done from videotapes. The first actions performed on each pair of objects was classified into one of four categories:

1. A mimic response-performing the exact action demonstrated by the experimenter (e.g., the child attempted to hammer the pegs but missed).

2. The intended action-completing the adult's action (e.g., hammering the pegs). This category included one case where it was clear that the child was attempting to complete the action but failed due to physical constraints (particularly in terms of eye-hand coordination).

3. An unrelated, novel action-the child performed a specific action, but the action was neither the demonstrated action nor the intended action of the adult.

4. No response/uncodable-any other action (or lack thereof).

Twenty-five percent of tapes were recoded for interjudge reliability. Two occasions of discrepancy $(M r=.98$, range $=0.75$ to 1.00$)$ were resolved when both coders watched the tape simultaneously and discussed it until they reached agreement.

\section{Results}

The proportion of times that children produced the adult's intended action first was the dependent measure of interest. Because a repeated measures ANOVA revealed no effect of gender on performance $(p>.85)$, data were collapsed for further analyses.

A repeated measures ANOVA revealed a trend toward a group effect for mimicking, $F(2,48)=2.99$, but post hoc analyses failed to detect significant differences. This was because the overall rate of mimicking was low. Out of 204 possible trials (4 times each for 51 children), a mimic response was observed only 11 times $(5.4 \%)$. It is interesting that only the youngest group (i.e., the LA group) demonstrated a substantial proportion of mimic responses $(13 \%$ of all trials; see Table 4).

There was no effect of set (i.e., whether the test set was canonical or noncanonical) on the rate of mimicking, but there was a significant effect of set on performance of the intended action, $t(50)=5.97$. A MANOVA revealed group differences within each set: canonical set, $F(2,48)=4.68$, partial $\eta^{2}=.16$, and noncanonical set, $F(2,48)=9.87$, partial $\eta^{2}=.29$. Post hoc Bonferroni tests for the canonical set found that the AD group differed from the MA group but not from the LA group. The two control groups did not differ from each other. These differences arose from higher rates of performing the intended actions for the MA group (1.94 times) and LA group (1.76 times) than for the AD group (1.35 times) .

Within the noncanonical set, post hoc Bonferroni tests revealed differences between the control groups and the $\mathrm{AD}$ group. The control groups did not differ from each other. Again, the MA group (1.53 times out of 2) and the LA group (1.00 time) performed the intended action more frequently than did the $\mathrm{AD}$ group (0.29 times). Thus, although there were substantial differences in performance between the two sets, there was also a consistency: In both the canonical and noncanonical action conditions, the MA group had the highest mean rate of performing the experimenter's intended action, the LA group mean was slightly lower, and the AD group had the lowest mean rate of intended action performance.

Table 4

Social Intention Without Word Learning: Rates of Mimicked and Intended Responses in Experiment 3 by Group

\begin{tabular}{lccc}
\hline & $\begin{array}{c}\text { AD group } \\
M(S D)\end{array}$ & $\begin{array}{c}\text { LA group } \\
M(S D)\end{array}$ & $\begin{array}{c}\text { MA group } \\
M(S D)\end{array}$ \\
\hline Canonical set & & & \\
Mimicked responses & & & \\
$\quad$ Number (out of 2) & $0.00(0.00)$ & $0.12(0.49)$ & $0.05(0.24)$ \\
$\quad$ Proportion & $0.00(0.00)$ & $0.06(0.24)$ & $0.03(0.12)$ \\
Intentional responses & & & \\
$\quad$ Number (out of 2) & $1.35(0.79)$ & $1.76(0.56)$ & $1.94(0.24)$ \\
$\quad$ Proportion & $0.68(0.39)$ & $0.88(0.28)$ & $0.97(0.12)$ \\
Noncanonical set & & & \\
Mimicked responses & & & \\
$\quad$ Number (out of 2) & $0.05(0.24)$ & $0.41(0.71)$ & $0.00(0.00)$ \\
$\quad$ Proportion & $0.03(0.12)$ & $0.21(0.36)$ & $0.00(0.00)$ \\
Intentional responses & & & \\
$\quad$ Number (out of 2) & $0.29(0.69)$ & $1.00(0.94)$ & $1.53(0.80)$ \\
$\quad$ Proportion & $0.15(0.34)$ & $0.50(0.47)$ & $0.77(0.40)$ \\
\hline
\end{tabular}

Note. $\mathrm{AD}=$ autism; $\mathrm{LA}=$ language age; $\mathrm{MA}=$ mental age. 


\section{Discussion}

All children identified and completed intended actions when they were canonical and consistent with their prior experience. For example, TD children were able to identify and complete intended actions between $88 \%$ and $97 \%$ of the time (LA group and MA group, respectively) and AD children enacted the intended actions $68 \%$ of the time. These findings suggest that the canonical set may not test children's inferential abilities at all. Rather, the high rates of "intended action" responses with the canonical set may be explained by children's prior knowledge of this set of toys.

In contrast, the noncanonical condition could not be solved based on previous experience and required children to infer the experimenter's goal based on her actions. Although this task was more challenging for all participants, TD children still discerned and demonstrated the intended action between $50 \%$ and $77 \%$ of the time (LA and MA groups, respectively). The AD group, however, was unable to solve the task, performing the intended action a mere $15 \%$ of the time.

Could it be that children in the AD group were simply less likely than TD children to imitate or explore the toys at all? This is a possibility, given high rates of uncodable responses. However, even though $\mathrm{AD}$ children were generally less likely to imitate adults or explore novel objects in Experiment 3, their overall performance with the familiar, canonical set was more comparable to the performance of TD children than to their performance with the noncanonical set. If the AD group's performance was universally poor in this task, differences between their performance and TD groups' performance could have been due to their reduced imitation and exploration. In light of the marked difference in performance when presented with the canonical versus noncanonical set, however, this explanation is unlikely.

There are several important links between this and prior studies. For example, Aldridge et al. (2000) also used a noncanonical action that defied object affordances in one post hoc study (a wooden mallet could be pulled apart instead of using it to hammer). Five AD children succeeded in hammering initially, and those same five were willing to pull the hammer apart a few days later. However, this study was not optimal, as the children were self-selected into the group requested to complete an intended action; that is, only those who successfully hammered the first time were requested to pull apart the hammer the second time. Furthermore, it is important to note that the control group in Aldridge et al.'s experiment was composed of very young children. Only 3 of the matched control TD children were older than 12 months, the minimum age at which successful completion of an intended action has been documented (Bellagamba \& Tomasello, 1999). The matched TD children in the Aldridge et al. experiment were too young to reasonably succeed at the task (for reasons that may have included gross motor skill). Thus, when AD children succeeded at the task, they were actually held to a low standard.

A second study is a near replication of the Aldridge et al. (2000) experiment. Carpenter et al. (2001) remedied some of the matching problems of the original experiment by matching AD children with children with developmental delays as assessed on a battery of verbal and nonverbal tests. In the Carpenter et al. study, however, AD children once again demonstrated the ability to complete a failed intention, just as they were able to demonstrate this completion in the canonical condition of the present experiment. Although Carpenter et al. used objects that could be manipulated in two ways, children lacked knowledge of the other uses of these objects. Thus, when an intended action was modeled, children probably did not consider it a violation of the way these objects were typically used. However, in the present study, which used common objects with familiar affordances such as a watering can and a tree, when a noncanonical relationship was modeled it was surely detected as such by children. Thus, the present noncanonical condition is arguably more demanding than the experiments conducted by Aldridge et al. (2000) and Carpenter et al. (2001), providing a clearer test of intentional understanding.

Experiment 3 revealed either that most AD children have difficulty determining the intentions of others (even in a task that does not involve word learning) or that they have a hard time using those inferences to guide their actions. In either case, our results suggest that $\mathrm{AD}$ children might not use a speaker's intentions to learn the meaning of a novel word.

\section{Experiment 4: Are AD Children Sensitive to Social Intention During Word Learning?}

Experiments 1 and 2 found that AD children are able to respond to perceptual cues and certain social cues. However, it is more difficult for AD children to use the intentions of another person to guide their behavior in ambiguous situations (Experiment 3, 
noncanonical). This result, coupled with the success of the $\mathrm{AD}$ group in the word-learning task of Experiment 2, suggests that word learning for $\mathrm{AD}$ children may be driven primarily by perceptual strategies that capitalize on attentional skills. Experiment 4 tested whether children could learn a word when the primary cues to word reference were communicative intentions.

Our experimental design was derived from Tomasello and colleagues' studies of intentional understanding (Akhtar, Carpenter, \& Tomasello, 1996; Akhtar \& Tomasello, 1996; Tomasello \& Barton, 1994). Children must infer that the adult is looking for a novel object that is labeled by a novel word. Children see the adult reject a number of objects in search of the "parlu" and must realize that an unrejected, previously unlabeled novel object is the intended referent and goal of the search. There have been some challenges to Tomasello and colleagues' assertion that this task taps intentional understanding via social cues. In 1998, Samuelson and Smith replicated the findings of Tomasello and colleagues omitting social cues. They explained the results based on memory processes and the target's contextual novelty at the moment the name was offered. The current experiment differs from both Akhtar and Tomasello's (1996) and Samuelson and Smith's (1998) tasks in that the context of each of the objects in the exposure and naming process is the same. Thus, our design ensures that contextual novelty in the naming situation cannot be implicated to explain any success that children may have in attaching a label to a referent.

Do AD and TD children recognize that the experimenter intends to locate a particular object in a situation of referential ambiguity? If they do, can they use that knowledge to map the novel word to a novel object? Based on previous work, both groups of TD children were predicted to find the "parlu" in our situation of referential ambiguity (Akhtar et al., 1996, Akhtar \& Tomasello, 1996; Samuelson \& Smith, 1998; Tomasello \& Barton, 1994; for a review see Tomasello, 1999). However, based on the findings with the noncanonical set in Experiment 3 and the assumption that this task requires children to understand the experimenter's intentions, the AD group should be unable to locate the correct object during testing.

\section{Method}

Participants. See the General Methodological Overview.

Procedure. Children were exposed to two sets of six objects each. Two familiar objects in each set were chosen because their labels are found in the vocabu- laries of very young children (Fenson et al., 1994). To verify that the objects were familiar to the actual participants, mothers were asked if their child knew the names of the four objects. Only one parent reported that their child did not comprehend all four words (and that child was only 15 months old). In an effort to ensure that the familiar objects were actually familiar to the children, the experimenter named each of the objects during the free-play session (e.g., "Do you want to play with the ball?").

In contrast, the remaining four objects in each set were novel and their names were not commonly found in young children's vocabularies (Fenson et al., 1994). Again, parents were asked if their children would recognize the objects and whether they knew the names of the objects. One object was moderately recognizable for the oldest TD children: 7 children were familiar with a honey dipper, and 4 children referred to it as a "Pooh toy". There was no difference in performance on Experiment 4 between these 7 children and the remaining 27 control children, nor was there any difference in performance with the honey dipper as compared to the other novel objects. No parents reported that their child knew the name of any other novel object.

Set A contained a ball and a plastic hammer (familiar objects), a flat plastic staple remover, a painted wooden honey dipper, a plastic egg separator, and a painted wooden stirrer (novel objects). Set B included a picture book and a toy frog (familiar objects), a square bottle opener, a travel lint remover, a hand-held fruit juicer, and a hexagonal abstract object (novel objects).

The experimenter first brought out a sack purse containing one set of six objects. Children played with each object separately (familiar objects first) for approximately $30 \mathrm{~s}$ before the experimenter placed that object back in the sack purse and gave them the next toy. After children explored all six objects, the experimenter said, "Let's find the parlu!" She reached into the purse, and retrieved one nontarget novel object. As it was displayed, she said, "No. That's not the parlu. I like it, but it's not the parlu." To highlight that the retrieved object was not what she was searching for, she shook her head and frowned while saying, "That's not the parlu" (Akhtar \& Tomasello, 1996; Tomasello \& Barton, 1994). To minimize the chance that children responded solely to her negative affect, she also smiled at each nontarget object and said that she liked it. This sequence was repeated two more times as she found and rejected the two remaining nontarget novel objects.

Rather than removing the fourth object (the target object intended to be labeled parlu), she pretended to 
be unable to find the parlu in the sack. After looking through the bag, she said, "Can you find the parlu?" and handed children the purse. While the children searched, she reminded them to look for the parlu. Once the children pulled an object out of the purse she congratulated them (regardless of whether they chose the correct object). The order of the novel objects during play and training was randomized.

Coding. Children's selections were classified into one of four categories: (a) the target object, (b) a different novel object, (c) a familiar object, or (d) no response/uncodable. The first object selected was coded as the child's choice. However, if a child picked a toy, and before showing it to the experimenter, said, "This is not the parlu" (or an equivalent phrase) and then continued to search, the first object that the child purposefully showed to the experimenter was coded as the child's choice. If a child picked up two objects simultaneously, the experimenter requested that the child select "just one" and coded that object as the child's choice. If after four prompts the child failed to select one object, the trial was coded as no response/ uncodable. When all the tapes were recoded to verify accuracy, no discrepancies were found $(r=1.0)$.

The dependent measure was whether children chose the correct object at test. Chance rates were based on all six objects (0.17) rather than just the four novel items (0.25) for two main reasons. First, all six objects were present and available as choices, and some children in each group selected the familiar object during test. Second, familiar objects were purposefully included at test to increase the number of objects available that had not been seen when the experimenter was pulling out novel objects and rejecting them, thereby decreasing the likelihood that children simply chose the object to which they had the least exposure.

\section{Results}

Data were analyzed in two ways. Between-group differences were explored using ANOVA, and withingroup differences from chance (i.e., 1 out of 6 , or 0.17 ) were examined using planned one-sample $t$ tests. Because a preliminary ANOVA revealed no effect of gender or testing session (Day 1 vs. Day 2) on proportion of correct choices, data were collapsed for further analyses.

A one-way ANOVA detected no between-group differences on the proportion of test trials where the correct object was chosen. Planned $t$ tests comparing the average proportion of times to chance level (.17) that each group chose the correct object at test revealed that the MA group chose the target object $50 \%$ of the time, $t(16)=3.17$, which exceeded chance. Likewise, the LA group selected the target object $41 \%$ of the time, $t(16)=2.50$, which was also significantly more often than expected by chance. The AD group, however, chose the target object only $26 \%$ of the time, $t(16)=1.13, p>.25$, not significantly more often than predicted by chance. Thus, only the two TD groups selected the correct object at test more frequently than predicted by chance ( 0.17 ; see Table 5$)$.

\section{Discussion}

The purpose of Experiment 4 was to determine whether children could infer an adult's intention to find a specific, novel object by name in an opaque sack. This task was clearly challenging-even TD children were correct only $40 \%$ to $50 \%$ of the time. To succeed at the task, participants had to realize that the adult was searching for a specific object that the child did not see her pull out of the sack and reject. They then had to assume that the unseen, unrejected object was labeled by the novel word parlu. They needed to recognize that the adult did not succeed in her search and that, therefore, none of the three objects shown during the failed search could be the parlu. Finally, the children had to search for a different object and map the word parlu onto that novel object. Although this may seem like an impossible task, the same demands were successfully made of 18- to 24month-olds (Akhtar, \& Tomasello, 1996; Samuelson \& Smith, 1998; Tomasello \& Barton, 1994). The present experiment replicates prior results demonstrating that TD children can discern the meaning of a novel word in this task (with difficulty).

While the MA and LA children evinced difficulty with the task, they nonetheless retrieved the target object more often than expected by chance. What prevented most of the AD group from succeeding? Several possibilities exist. First, general cognitive processes, such as memory, were clearly needed to succeed (Samuelson \& Smith, 1998). In Experiment 2,

Table 5

Social Intention With Word Learning: Frequency With Which Children Chose the Target Object in Experiment 4 by Group

\begin{tabular}{lccc}
\hline Correct selections & AD group & LA group & MA group \\
\hline 0 & 10 & 7 & 6 \\
1 & 5 & 6 & 5 \\
2 & 2 & 4 & 6 \\
\hline
\end{tabular}

Note. $\mathrm{AD}=$ autism $; \mathrm{LA}=$ language age; $\mathrm{MA}=$ mental age. 
the $\mathrm{AD}$ group demonstrated that they could rapidly learn and remember words. Moreover, the MA group was specifically matched to the AD group on nonverbal mental abilities to control for the effects of general cognitive processing skills, and the LA group had less developed cognitive skills than the AD group. Although it is conceivable that children from the AD group did not understand the language of the task, the current design theoretically controlled for this possibility by using a language-matched comparison group of TD children. Therefore, it seems unlikely that either mental or language delays are the sole explanation for the results (though future research should explore whether AD children can succeed at this task when cognitive demands are reduced).

Another possible explanation is that AD children simply did not attend to the adult and her movements during the task. This is unlikely because all children watched closely as each object was removed from the purse during training. Similarly, all children were engaged in the task sufficiently to begin searching through the bag for the parlu within seconds of receiving the purse. Minimal prompting was required for any child.

A third possibility is that AD children either did not realize that the experimenter failed to find the desired object or they could not use that information to guide word learning. It is possible that the failure occurred at the point of word learning per se; that is, the AD children were able to recognize the experimenter's failed intention but were unable to use that information to determine which object was the parlu. Recent research indicates that some AD children have some understanding of intentions and have the ability to engage others in intentional interaction (Carpenter et al., 2001; Nadel et al., 2000). If that is true, and yet the AD group did not generally succeed, it may be that using intentional understanding in the service of word learning is especially difficult for AD children.

Another possibility is based on extensive prior research indicating that $\mathrm{AD}$ children often have trouble going beyond surface actions to infer another person's intentions (Baron-Cohen, 1995; BaronCohen, Tager-Flusberg, \& Cohen, 1993; Bloom, 2000; Hobson, 1993; Kasari, Mundy, \& Sigman, 1990; Klin \& Volkmar, 1993; Leekham et al., 2000; Loveland \& Landry, 1986; Tager-Flusberg, 1999, 2001; Warreyn et al., 2005; but see Aldridge et al. 2000; Carpenter et al., 2001; Nadel, 2004). On this view, children in the AD group may not have moved beyond a reliance on attentional, perceptual cues to an understanding of intentions in an effort to complete the task. In light of prior research, and considering the results from the noncanonical set in Experiment 3 and the overall results in Experiment 4, it seems likely that $\mathrm{AD}$ children have, at best, a fragile understanding of others' intentions. However, in the current experiment, it is impossible to know whether the $\mathrm{AD}$ children were unable to infer the adult's intention or whether they simply had difficulty using intentional information to guide word learning. In either case, the result was the same: $\mathrm{AD}$ children did not learn the meaning of a novel word when a task required an understanding of speaker intention.

Looking across tasks: The role of intention. While each task provides valuable insight into the different ways that intention and attention exert their influence, it is crucial to look across tasks to understand how intention in general is related to language development and cognitive skill. This article advanced the hypothesis that the ability to discern the intent of another plays a special role in language acquisition. Looking across tasks, two specific hypotheses emerge: First, if vocabulary acquisition is uniquely facilitated by understanding the intentions of others, children who scored higher on tasks requiring intention should also have scored higher on a test of vocabulary (PPVT). Thus, the intent task composite score should account for a significant amount of variance in performance on the PPVT, more so than general mental ability (DAS) or chronological age. Second, if vocabulary and intentional understanding have a special relationship that transcends the effect of general mental ability and chronological age, scores on nonintent tasks should not account for a significant amount of variance in the PPVT.

To examine relationships among intention, vocabulary, chronological age, and nonverbal MA, tasks from the four studies were split into two groups: tasks requiring intentional understanding to succeed and tasks less reliant on intentional understanding. A logical analysis suggested that three of the tasks (the conflict test trial of Experiment 2, the noncanonical set of Experiment 3, and Experiment 4) were qualitatively different from the other tasks (Experiment 1 and the coincidental test trial of Experiment 2). Thus, we combined the first set into a group labeled intent tasks and the second into nonintent tasks. The canonical set of Experiment 3 was not included in either group, as its status as an intention-requiring task was ambiguous (i.e., participants saw the experimenter fail to enact a behavior, but the action was in line with object affordances and thus did not require an understanding of intention). A composite score was created for the intent and nonintent tasks by standardizing scores on each task and averaging those scores. 
Three stepwise linear regression analyses were conducted, one each for the AD, LA, and MA groups. In each regression, chronological age, DAS scores, nonintent scores, and intent scores were entered stepwise (criterion to enter, $p<.05$, to exclude, $p>.10$ ). The dependent variable was PPVT score. The AD group regression revealed that intent task scores accounted for $68 \%$ of variance in PPVT scores $\left(R^{2}=.68\right)$ and DAS scores accounted for an additional $9 \%\left(\Delta R^{2}=.09\right)$. Neither chronological age nor nonintent task scores were significantly predictive of PPVT scores. The LA and MA group regressions revealed that chronological age accounted for $88 \%$ and $84 \%$ of variance in PPVT scores, respectively $\left(R^{2}: \mathrm{LA}=.89, \mathrm{MA}=.84\right)$. Neither DAS nor intent/nonintent composite scores were significantly and independently related to PPVT scores for the LA or MA groups.

Both of our initial hypotheses were confirmed for the AD group. First, it appears that the ability to use the hidden intentions of others is especially related to vocabulary development in AD children. Second, performance on tasks that did not require the $\mathrm{AD}$ children to go beyond surface perceptions was unrelated to PPVT scores. In the TD groups, chronological age trumped all other variables as a predictor of PPVT scores. This is unsurprising in light of the high intercorrelations among age, PPVT, DAS, and performance for both the LA and the MA groups. Even more important, an increased understanding of the intentions of others develops in tandem with chronological age in TD children (Akhtar, \& Tomasello, 1996; Samuelson \& Smith, 1998; Tomasello \& Barton, 1994) but does not necessarily do so in AD children.

The finding that performance on tasks requiring intentional understanding is uniquely predictive of PPVT scores in the AD group is remarkable for two reasons. First, DAS and PPVT scores were highly correlated with each other for the AD, LA, and MA groups ( $r \mathrm{~s}=.79, .89$, and .82 , respectively). Thus, our analysis examines the unique relationship between language and intentionality above and beyond what is accounted for by cognitive ability; that is, the relationship between language and intentionality holds even after controlling for the correlation between DAS and PPVT scores. Second, sample sizes were small-only 17 children per group. Thus, it is particularly telling that even with high intercorrelations and small sample sizes, a composite score from tasks requiring an understanding of intent was nonetheless of special predictive value for the vocabulary of the AD group. This result is consistent with Fisher, Happé, and Dunn's (2005) conclusion that more advanced language skills (particularly grammar but also vocabulary) predict the performance of $\mathrm{AD}$ children on theory-of-mind tasks. Together, these findings suggest that understanding the intentions of others may allow AD children to acquire a larger vocabulary. On this view, a more advanced understanding of the hidden intentions of others may, as a byproduct of that understanding, provide access to a richer vocabulary - one that goes beyond perception.

It must be noted that whereas performance on the intentional tasks predicted PPVT scores in the AD group, performance on the nonintentional tasks did not. This may be surprising considering that social attention (Experiment 1) and word learning in the context of social attention (Experiment 2) might reasonably be related to vocabulary in an AD population just as are social intentional abilities. However, the current results suggest that while social attention is sufficient for word learning in a limited context, some understanding of social intention facilitates the most extensive vocabulary growth. This finding is a clear indication that social attentional abilities can be used to acquire object labels when a multitude of salient cues (social and perceptual) are in alignment and the task is simple, but it is nonetheless the ability to use the intentions of others in more ambiguous situations that is truly predictive of ultimate vocabulary development in AD children.

Correlations: Task performance and DAS and PPVT scores. The variable levels of attentional and intentional understanding found in AD populations demands that the present results be examined at the individual as well as the group level. This strategy helps researchers avoid making gross generalizations and missing key interrelations between different parts of a single study (Tager-Flusberg, 1999, 2001, 2004).

Experiment 4 was the most demanding for all groups. As such, it is interesting to see whether performance in Experiments 1 to 3 was correlated with the AD group's final performance in Experiment 4. These results are presented in Table 6. Only three significant correlations emerged with Experiment 4: PPVT raw scores $(r=.56)$, total time spent looking at the target object in Experiment $1(r=.50)$, and the number of new words learned in Experiment 2 (as evidenced by a V-shaped pattern across test, newlabel, and recovery trials; $r=.67$; not in Table 6 ). The relative dearth of between-task correlations suggests that whereas each experiment may have tapped its intended construct, the relationship between them could have been stronger. On the other hand, children's ability to attach a label to a novel object on the very challenging task of Experiment 4 might reasonably be related to a combined ability to follow attentional cues in Experiment 1 and quickly map 
words to referents in Experiment 2. Although the absence of a correlational relationship between Experiments 3 and 4 is puzzling in light of our attempt to access the same construct of social intentional understanding in both, the results of our composite intent score regression analyses suggest that these scores are compatible. This pattern of correlations between experiments and verbal-mental ability scores calls attention to the diversity of ability found in $\mathrm{AD}$ children.

\section{General Discussion}

Disentangling attention to social cues from intentional understanding is central for understanding the role that social interaction plays in early word learning. TD children attend to social cues and use these same cues to infer speaker intent. Based on prior research, it was hypothesized that $A D$ children would rely relatively less on intentional information and more on attentional cues. Four experiments compared the differential abilities of TD children with those of AD children in nonlinguistic and word-learning tasks that required the use of social attention, social intention, or both.

\section{Can AD Children Detect Social Cues?}

The results suggest that all children pay attention to social cues (Experiment 1). At a minimum, even AD children use attentional social cues to learn words (Experiment 2, coincidental condition). Consistent with the literature, however, $\mathrm{AD}$ children had more

Table 6

AD Group Pearson's Correlation Matrix

\begin{tabular}{lcccccccc}
\hline & PPVT & DAS & T1 & T2-i & T2-b & T3-c & T3-n & T4 \\
\hline PPVT & 1.00 & $.79^{*}$ & .39 & .27 & $.66^{*}$ & $.50^{*}$ & $.55^{*}$ & $.56^{*}$ \\
DAS & & 1.00 & .32 & .20 & $.64^{*}$ & .41 & .43 & .46 \\
T1 & & & 1.00 & -.05 & .17 & -.29 & -.20 & $.50^{*}$ \\
T2-i & & & & 1.00 & .23 & .31 & .15 & .26 \\
T2-b & & & & & 1.00 & .44 & .38 & .31 \\
T3-c & & & & & & 1.00 & .26 & .31 \\
T3-n & & & & & & 1.00 & .05 \\
T4 & & & & & & & 1.00 \\
\hline
\end{tabular}

Note. Each task used different measures. Task $1(\mathrm{~T} 1)=$ time looking at target during test; Task $2=$ number of correct selections during the test trials for the interesting object (T2-i) and the boring object (T2-b); Task $3=$ performance of the intended action with the canonical set (T3-c) and the noncanonical set (T3-n); and Task 4 (T4) $=$ choosing the target object. AD = autism; PPVT = Peabody Picture Vocabulary Test; DAS $=$ Differential Abilities Scales. ${ }^{*} p<.05$. trouble learning words for objects that were not interesting to them (Experiment 2, conflict condition). Experiment 3 examined nonlanguage intentional understanding and found that only TD children consistently used a speaker's social intentions to complete intended but unfulfilled actions. Finally, AD children fared worse than TD children in a word-learning task that required sensitivity to speaker intent (Experiment 4).

These results reinforce the view that $\mathrm{AD}$ children are not socially impaired in a broad sense (Aldridge et al., 2000; Bayliss \& Tipper, 2005; Carpenter et al., 2001; Hornbeck, 2001; Kylliäinen \& Hietanen, 2004; Nadel, 2004; Okada et al., 2004). AD children as a group followed social gestures but only resembled TD children in tasks where there was perceptual reinforcement or predictable outcomes (Experiment 1; Experiment 2, coincidental; Experiment 3, canonical).

There are two potential explanations for these results. First, these studies seem to replicate prior studies suggesting that some AD children have less access to speaker intentions and that this limits their ability to learn object-word pairings as well as to reproduce actions that are not perceptually obvious (Baron-Cohen, 1995; Bloom, 2000; Charman, 2000; Charman et al., 1998; Griffin, 2002; Peterson, 2005; Rogers \& Pennington, 1991; Ruffman, 2000, Ruffman et al., 2001; Tager-Flusberg, 1999, 2001; Tomasello, 1999). This conclusion must be interpreted with caution, as heterogeneity of skills in the AD population defies broad generalizations.

A second explanation for the generally poorer performance of the $\mathrm{AD}$ population is that $\mathrm{AD}$ children experience difficulty in combining sources of information and the intent tasks were simply too complex (Happé \& Frith, 2006). In the simplest situation (Experiment 1), when asked to look at the object the examiner was holding, both $\mathrm{AD}$ and TD children succeeded. Differences occurred when the tasks placed heavier cognitive demands on the children (e.g., violating expected behaviors as in Experiment 3, noncanonical). Accessing social intent is simply a more complex task than attending to interesting or salient perceptual cues. In light of our cross-task regression analyses, however, this explanation is unlikely. If mere complexity were the problem for $\mathrm{AD}$ children when faced with tasks requiring social intent, DAS scores and chronological age should have been more uniquely predictive of vocabulary than the composite score on intent tasks. The fact that scores on intent tasks but not nonintent tasks or DAS scores were the most useful for predicting vocabulary scores suggests that something about intentional understanding per se is crucial to language and that 
complexity alone does not explain the difficulty that $\mathrm{AD}$ children had with intent tasks.

\section{Implications for Word Learning}

These results begin to define the relative contributions of attentional and intentional cues to word learning. AD children can use attentional information to map word to world. Our findings are thus consistent with recent research by Baron-Cohen et al. (1997) and Preissler and Carey (2005), who demonstrated that $\mathrm{AD}$ children are capable of learning words in tasks that require no more than word-object associations. Furthermore, AD children, who appear to operate primarily via perceptual/associative learning, show evidence of the guiding principles thought to be crucial in word acquisition. For example, in the coincidental condition of Experiment 2 (in which participants learned names for objects they preferred), both AD and TD children demonstrated some understanding that a novel name labels a previously unnamed object on the new-label trial. This suggests that they were operating via mutual exclusivity (Markman et al., 2003) or N3C (Golinkoff et al., 1994). There is also evidence to suggest that high-functioning $\mathrm{AD}$ children can acquire vocabulary levels that are virtually indistinguishable from TD children (Jarrold et al., 1997; Kjelgaard \& Tager-Flusberg, 2001; Phemister, 2005; Schnur, 2005; Sciutto \& Cantwell, 2005; Tager-Flusberg, 2006). Set within the broader literature, this study challenges the necessary and sufficient role of inferring speaker intent in word learning and explores the boundaries of vocabulary knowledge acquired through attentional cues alone.

Although intention is not necessary for word learning, it appears to play an important role in typical language development. A rich literature suggests that infants acquire their first words through word-object association (Colunga \& Smith, 2005; Golinkoff \& Hirsh-Pasek, 2006; Oviatt, 1980, 1982; Pruden et al., 2006; Werker, Cohen, Lloyd, Casasola, \& Stager, 1998; Woodward, Markman, \& Fitzsimmons, 1994; but see Tomasello, 1999) and that by 18 months of age, most children show evidence of understanding and using speaker intent in the service of word learning (Akhtar, \& Tomasello, 1996; Baldwin et al., 1996; Hollich et al., 2000; Tomasello \& Barton, 1994). Once an understanding of social intention is harnessed in a word-learning situation, TD children may capitalize on expert speakers' linguistic repertoire and rapidly increase their vocabularies. This hypothesis is supported by the present fact that $\mathrm{AD}$ children who were more sensitive to social intent also had better language skills.
The emergentist coalition model suggests that word-learning strategies, such as attention to social cues and sensitivity to speaker intent, lie on a continuum (Hollich et al., 2000). At one end of the continuum are learners who use association to link objects to sounds-and only do so from their point of view. Pruden et al.'s (2006) data support this hypothesis: Ten-month-olds incorrectly mapped a new word to an interesting object even though the speaker intended to name a boring object. By 12 months, babies made progress and no longer made mismappings. However, they still could not learn the name of an object that they did not find inherently interesting (Hollich et al., 2000). Thus, 12-month-olds notice attentional cues offered by a speaker but cannot always recruit this information in the service of word learning. The other end of the continuum might be anchored by learners who use an understanding of social intention to map words to referents. As Hollich et al. (2000) found, by 19 and especially by 24 months of age, these flexible word learners are able to take the speaker's point of view and map a word to a referent intended by the speaker, regardless of whether the referent is boring or interesting.

Whereas TD children usually operate via intentional understanding by 24 months, some AD children have difficulty using social intentions to guide their behavior and may remain closer to the attentional end of the continuum. However, attentional mechanisms are clearly effective word-learning tools: Both very young infants and many older AD children are able to learn new words with relative ease when the situation is perceptually clear and multiple cues to word reference overlap. This is consistent with theories suggesting the importance of overlapping cues (i.e., congruent social and perceptual signals) in early word learning (Hollich et al., 2000; Waxman \& Booth, 2003; Woodward et al., 1994). A hybrid theory that emphasizes multiple word-learning strategies that change over time and context may also explain how many AD children (or children with autism spectrum disorders broadly defined) acquire fairly rich vocabularies (Jarrold et al., 1997; Kjelgaard \& TagerFlusberg, 2001; Phemister, 2005; Schnur, 2005; Sciutto \& Cantwell, 2005; Tager-Flusberg, 2006). Hybrid theories also explain how the creative efforts of parents, teachers, and therapists who follow a child's line of attention in learning tasks yoke attentional cues to intentional cues (McDuffie et al., 2005, 2006) and actually improve a child's intentional understanding via language development (Fisher et al., 2005).

The current study has important implications for facilitating language development in AD populations. Although the transition from attentional 
strategies to intentional strategies is only dimly understood, interventions that build on the social and attentional skills children bring to the task of word learning improve both social and language skills (Ingersoll, Dvortcsak, Whalen, \& Sikora, 2005; Loncola \& Craig-Unkefer, 2005). One promising randomized controlled treatment study along these lines was conducted by Aldred, Green, and Adams (2004). They found that children whose parents were trained to tailor communication to their children's individual competencies made significant gains in their Autism Diagnostic Observation Schedule total score, primarily in reciprocal social interaction, expressive language, and communicative initiation. These findings suggest that capitalizing on AD children's individual strengths can best support their development in both the social and language realms.

Although the current research represents a first step toward understanding the respective roles of attention and intention in word learning, it is not without limitations. Our experiments were conducted with a relatively small number of participants, and the context of word learning was narrow. We did not explore how word learning occurs in more realistic situations, nor did we assess whether our participants possessed additional strengths to facilitate word learning. Moreover, our MA control group was a questionable match to the $\mathrm{AD}$ group. It has been suggested that future studies should use matched children with a specific language delay (Tager-Flusberg, 2004; but see Burack et al., 2004; Charman, 2004). Furthermore, our LA group was assembled using PPVT scores, a matching method that has been called into question for overestimating the verbal abilities of AD children (Shaked \& Yirmiya, 2004).

Even with these limitations, however, the current research is a valuable step toward understanding the different roles that social attention and intention play in word learning. It suggests that although understanding the intentions of others is not necessary for word learning, such an understanding greatly facilitates the acquisition of a richer vocabulary in $A D$ children. Thus, the results of this study add to our knowledge of the essential ingredients for word learning in a TD population, as well as clarify the kinds of abilities that AD children can and do use to learn words.

\section{References}

Adamson, L. B., Bakeman, R., \& Deckner, D. F. (2004). The development of symbol-infused joint engagement. Child Development, 75, 1171-1187.
Akhtar, N. (2005). The robustness of learning through overhearing. Developmental Science, 8, 199-209.

Akhtar, N., Carpenter, M., \& Tomasello, M. (1996). The role of discourse novelty in early word learning. Child Development, 67, 635-645.

Akhtar, N. \& Tomasello, M. (1996). Two-year-olds learn words for absent objects and actions. British Journal of Developmental Psychology, 14, 79-93.

Akhtar, N., \& Tomasello, M. (2000). The social nature of words and word learning. In R. M. Golinkoff, K. Hirsh-Pasek, L. Bloom, L. B. Smith, A. L. Woodward, N. Akhtar, et al.. (Eds.), Becoming a word-learner: A debate on lexical acquisition (pp. 115-135). New York: Oxford University Press.

Aldred, C., Green, J., \& Adams, C. (2004). A new social communication intervention for children with autism: Pilot randomised controlled treatment study suggesting effectiveness. Journal of Child Psychology E Psychiatry, 45, $1420-1430$.

Aldridge, M. A., Stone, K. R., Sweeney, M. H., \& Bower, T. G. R. (2000). Preverbal children with autism understand the intentions of others. Developmental Science, 3, 294-301.

American Psychiatric Association. (1994). Diagnostic and statistical manual of mental disorders (4th ed.). Washington, DC: Author.

Baldwin, D. A., Markman, E. M., Bill, B., Desjardins, N., Irwin, J. M., \& Tidball, G. (1996). Infants' reliance on a social criterion for establishing word-object relations. Child Development, 67, 3135-3153.

Baron-Cohen, S. (1995). Mindblindness: An essay on autism and theory of mind. Cambridge, MA: MIT Press.

Baron-Cohen, S., Baldwin, D. A., \& Crowson, M. (1997). Do children with autism use the speaker's direction of gaze strategy to crack to code of language? Child Development, $68,48-57$.

Baron-Cohen, S., Tager-Flusberg, H., \& Cohen, D. J. (1993). Understanding other minds: Perspectives from autism. New York: Oxford University Press.

Bayliss, A. P., \& Tipper, S. P. (2005). Gaze and arrow cueing of attention reveals individual differences along the autism spectrum as a function of target context. British Journal of Psychology, 96, 95-114.

Bellagamba, F., \& Tomasello, M. (1999). Re-enacting intended acts: Comparing 12- and 18-month-olds. Infant Behavior and Development, 22, 277-282.

Bloom, L., \& Tinker, E. (2001). The intentionality model and language acquisition: Engagement, effort, and the essential tension in development. Monographs of the Society for Research in Child Development, 66(4, Serial No. 267).

Bloom, P. (2000). How children learn the meanings of words. Cambridge, MA: MIT Press.

Booth, A., Waxman, S. R., \& Huang, Y. T. (2005). Conceptual information permeates word learning in infancy. Developmental Psychology, 41(3), 491-505.

Bregman, J. D. (2005). Definitions and characteristics of the spectrum. In D. Zager (Ed.), Autism spectrum disorders: 
Identification, education, and treatment (3rd ed., pp. 3-46). Mahwah, NJ: Erlbaum.

Burack, J. A., Iarocci, G., Flanagan, T. D., \& Bowler, D. M. (2004). On mosaics and melting pots: Conceptual considerations of comparison and matching strategies. Journal of Autism and Developmental Disorders, 34, 65-73.

Carey, S. (1978). The child as word learner. In M. Halle, J. Bresnan, \& G. A. Miller (Eds.), Linguistic theory and psychological reality. Cambridge, MA: MIT Press.

Carpenter, M., Akhtar, N., \& Tomasello, M. (1998). Fourteenthrough 18-month-old infants differentially imitate intentional and accidental actions. Infant Behavior and Development, 21, 315-330.

Carpenter, M., \& Call, J. (2002). The chemistry of social learning. Developmental Science, 5, 22-24.

Carpenter, M., Pennington, B. F., \& Rogers, S. J. (2001). Understanding of others' intentions in children with autism. Journal of Autism and Developmental Disorders, 31, $589-599$.

Centers for Disease Control and Prevention. (2007a). Prevalence of Autism Spectrum Disorders-Autism and Developmental Disabilities Monitoring Network, Six Sites, United States, 2000. Surveillance Summaries, MMWR, 56, SS-1, 1-10.

Centers for Disease Control and Prevention. (2007b). Prevalence of Autism Spectrum Disorders-Autism and Developmental Disabilities Monitoring Network, 14 Sites, United States, 2002. Surveillance Summaries, MMWR, 56, SS-1, 12-27.

Chan, A. S., Cheung, J., Leung, W. M., Cheung, R., \& Cheung, M. (2005). Verbal expression and comprehension deficits in young children with autism. Focus on Autism \& Other Developmental Disabilities, 20(2), 117-124.

Charman, T. (2000). Theory of mind and the early diagnosis of autism. In S. Baron-Cohen, H. Tager-Flusberg, \& D. Cohen (Eds.), Understanding other minds: Perspectives from developmental cognitive neuroscience (pp. 422-441). New York: Oxford University Press.

Charman, T. (2004). Matching preschool children with autism spectrum disorders and comparison children for language ability: Methodological challenges. Journal of Autism and Developmental Disorders, 34, 59-64.

Charman, T., Baron-Cohen, S., Swettenham, J., Baird, G., Drew, A., \& Cox, A. (2003). Predicting language outcome in infants with autism and pervasive developmental disorder. International Journal of Language $\mathcal{E}$ Communication Disorders, 38, 265-285.

Charman, T., Baron-Cohen, S., Swettenham, J., Cox, A., Baird, G., \& Drew, A. (1998). An experimental investigation of social-cognitive abilities in infants with autism: Clinical implications. Infant Mental Health Journal, 19, 260-275.

Charman, T., \& Huang, C. T. (2002). Delineating the role of stimulus enhancement and emulation learning in the behavioral re-enactment paradigm. Developmental Science, $5,25-27$.

Chen, H., \& Peng, D. (1995). Do young children learn words from TV? A study of incidental learning. Psychological Science (China), 18, 22-28.
Cimpian, A., \& Markman, E. (2005). The absence of a shape bias in children's word learning. Developmental Psychology, 41, 1003-1019.

Colunga, E., \& Smith, L. B. (2005). From the lexicon to expectations about kinds: A role for associative learning. Psychological Review, 112, 347-382.

Cottrell, G. W., \& Plunkett, K. (2002). Acquiring the mapping from meaning to sounds. In T. A. Polk (Ed), Cognitive modeling (pp. 661-689). Cambridge, MA: MIT Press.

Diesendruck, G., \& Bloom, P. (2003). How specific is the shape bias? Child Development, 74, 168-178.

Diesendruck, G., Markson, L., \& Akhtar, N. (2004). Twoyear-olds' sensitivity to speakers' intent: An alternative account of Samuelson and Smith. Developmental Science, 7, 33-41.

Downs, A., \& Smith, T. (2004). Emotional understanding, cooperation, and social behavior in high-functioning children with autism. Journal of Autism and Developmental Disorders, 34, 625-635.

Dube, W. V., MacDonald, R. P. F., \& Mansfield, R. C. (2004). Toward a behavioral analysis of joint attention. Behavior Analyst, 27, 197-207.

Dunn, L., \& Dunn, L. (1997). Peabody Picture Vocabulary Test (3rd ed.). Circle Pines, MN: American Guidance Service.

Elliott, C. D. (1990). The nature and structure of children's abilities: Evidence from the Differential Abilities Scales. Journal of Psychoeducational Assessment, 8, 376-390.

Fenson, L., Dale, P. S., Reznick, J. S., Bates, E., Thal, D. J., \& Pethick, S. J. et al. (1994). Variability in early communicative development. Monographs of the Society for Research in Child Development, 59(5, Serial No. 242).

Fisher, N., Happé, F., \& Dunn, J. (2005). The relationship between vocabulary, grammar, and false belief task performance in children with autistic spectrum disorders and children with moderate learning difficulties. Journal of Child Psychology \& Psychiatry \& Allied Disciplines, 46, 409-419.

Ghaziuddin, M., \& Mountain-Kimchi, K. (2004). Defining the intellectual profile of Asperger syndrome: Comparison with high-functioning autism. Journal of Autism $\mathcal{E}$ Developmental Disorders, 34, 279-284.

Golinkoff, R. M., \& Hirsh-Pasek, K. (2006). Baby wordsmith: From associationist to social sophisticate. Current Directions in Psychological Science, 15, 30-33.

Golinkoff, R., Mervis, C., \& Hirsh-Pasek, K. (1994). Early object labels: The case for a developmental lexical principles framework. Journal of Child Language, 21, 125-156.

Gordon, B., \& Elliott, D. (2001). Assessment with the Differential Ability Scales. In J. Andrews, D. H. Saklofske, \& H. L. Janzen (Eds.), Handbook of psychoeducational assessment: Ability, achievement, and behavior in children (pp 65-101). San Diego, CA: Academic Press.

Grice, S. J., Halit, H., Farroni, T., Baron-Cohen, S., Bolton, P., \& Johnson, M. H. (2005). Neural correlates of eye-gaze detection in young children with autism. Cortex, 41, $342-353$.

Griffin, R. (2002). Social learning in the non-social: Imitation, intentions, and autism. Developmental Science, 5, 30-32. 
Hale, C. M., \& Tager-Flusberg, H. (2003). The influence of language on theory of mind: A training study. Developmental Science, 6, 346-359.

Hale, C. M., \& Tager-Flusberg, H. (2005a). Social communication in children with autism. International Journal of Research \& Practice, 9, 157-178.

Hale, C. M., \& Tager-Flusberg, H. (2005b). Brief report: The relationship between discourse deficits and autism symptomatology. Journal of Autism \& Developmental Disorders, 35, 519-524.

Happé, F., \& Frith, U. (2006). The weak coherence account: Detail-focused cognitive style in autism spectrum disorders. Journal of Autism and Developmental Disorders, 36, $5-25$.

Heerey, E. A., Capps, L. M., \& Keltner, D. (2005). Understanding teasing: Lessons from children with autism. Journal of Abnormal Child Psychology, 33, 55-68.

Helfant, M. (2004). Language delays and cognitive ability. Dissertation Abstracts International: Section B: The Sciences and Engineering, 65 (4-B), 2120. (UMI No. AAT 3129140)

Heyes, C. M. (2001). Causes and consequences of imitation. Trends in Cognitive Science, 5, 253-261.

Hirsh-Pasek, K., Golinkoff, R., Hennon, E., \& Maguire, M. (2004). Hybrid theories at the frontier of developmental psychology: The emergentist coalition model of word learning as a case in point. In G. Hall \& S. Waxman (Eds.), Weaving a lexicon (pp. 173-204). Cambridge, MA: MIT Press.

Hobson, R. P. (1993). Autism and the development of mind. Hillsdale, NJ: Erlbaum.

Hoff, E. (2003). The specificity of environmental influence: Socioeconomic status affects early vocabulary development via maternal speech. Child Development, 74, 1368-1378.

Hoff, E., \& Tian, C. (2005). Socioeconomic status and cultural influences on language. Journal of Communication Disorders, 38, 271-278.

Hollich, G. J., Hirsh-Pasek, K., \& Golinkoff, R. M. (2000). Breaking the language barrier: An emergentist coalition model for the origins of word learning. Monographs of the Society for Research in Child Development, 65(3, Serial No. 262).

Hornbeck, V. S. (2001). Understanding of intention and imitation in young children with autism, children with other developmental disabilities and children with typical development. Dissertation Abstracts International: Section B: The Sciences and Engineering, 62 (3-B), 1579. (UMI No. AAT 3006974).

Houston-Price, C., Plunkett, K., \& Harris, P. (2005). “Wordlearning wizardry" at 1;6. Journal of Child Language, 32, $175-189$.

Huang, C. T., Heyes, C., \& Charman, T. (2002). Infants' behavioral re-enactment of "failed attempts": Exploring the roles of emulation learning, stimulus enhancement, and understanding of intentions. Developmental Psychology, 38, 840-855.

Ingersoll, B., Dvortcsak, A., Whalen, C., \& Sikora, D. (2005). The effects of a developmental, social-pragmatic language intervention on rate of expressive language production in young children with autistic spectrum disorders. Focus on Autism \& Other Developmental Disabilities, 20, 213-222.

Jarrold, C., Boucher, J., \& Russell, J. (1997). Language profiles in children with autism. Autism, 1, 57-76.

Kasari, C., Mundy, P., \& Sigman, M. (1990). Affect sharing in the context of joint attention interactions of normal, autistic, and mentally retarded children. Journal of Autism and Developmental Disorders, 20, 87-100.

Kjelgaard, M.M., \& Tager-Flusberg, H. (2001). An investigation of language impairment in autism: Implications for genetic subgroups. Language and Cognitive Processes, 16, 287-308.

Klin, A., \& Volkmar, F. (1993). The development of individuals with autism: Implications for the theory of mind hypothesis. In S. Baron-Cohen, H. Tager-Flusberg, \& D. J. Cohen (Eds.), Understanding other minds: perspectives from autism (pp. 317-331). New York: Oxford University Press.

Kruschke, J. K. (2003). Attention in learning. Current Directions in Psychological Science, 12, 171-175.

Kylliäinen, A., \& Hietanen, J. K. (2004). Attention orienting by another's gaze direction in children with autism. Journal of Child Psychology and Psychiatry, 45, 435-444.

Leekham, S. R., Hunnisett, E., \& Moore, C. (1998). Targets and cues: Gaze-following in children with autism. Journal of Child Psychology and Psychiatry, 39, 951-962.

Leekham, S. R., Lopez, B., \& Moore, C. (2000). Attention and joint attention in preschool children with autism. Developmental Psychology, 36, 261-273.

Loncola, J. A., \& Craig-Unkefer, L. (2005). Teaching social communication skills to young urban children with autism. Education and Training in Developmental Disabilities, 40, 243-263.

Loveland, K., \& Landry, S. (1986). Joint attention and language in autism and developmental language delay. Journal of Autism and Developmental Disorders, 16, $335-348$.

Markman, E. M., Wasow, J. L., \& Hansen, M. B. (2003). Use of the mutual exclusivity assumption by young word learners. Cognitive Psychology, 47, 241-275.

McDuffie, A., Yoder, P., \& Stone, W. (2005). Prelinguistic predictors of vocabulary in young children with autism spectrum disorders. Journal of Speech, Language $\mathcal{E}$ Hearing Research, 48, 1080-1097.

McDuffie, A. S., Yoder, P., \& Stone, W. (2006). Labels increase attention to novel objects in children with autism and comprehension-matched children with typical development. Autism, 10, 288-301.

Meltzoff, A. N. (1995). Understanding the intentions of others: Re-enactment of intended acts by 19-month-old children. Developmental Psychology, 31, 838-850.

Merriman, W. E., \& Evey, J. A. (2005). The nominal passover effect depends on addressee age, speaker goal, and object similarity. Child Development, 76, 1185-1201.

Moore, C., Angelopoulos, M., \& Bennet, P. (1999). Word learning in the context of referential and salience cues. Developmental Psychology, 35, 60-68. 
Mundy, P. (2003). The neural basis of social impairments in autism: The role of the dorsal medial-frontal cortex and anterior cingulate system. Journal of Child Psychology $\mathcal{E}$ Psychiatry, 44, 793-809.

Nadel, J. (2004). Do children with autism understand imitation as intentional interaction? Journal of Cognitive and Behavioral Psychotherapies, 4, 165-177.

Nadel, J., Croue, S., Mattlinger, M., Canet, P., Hudelot, C., Lecuyer, C., et al. 2000). Do children with autism have expectations about the behaviours of unfamiliar people? Autism, 4, 133-145.

Okada, T., Sato, W., \& Murai, T. (2004). Eye gaze triggers visuospatial attentional shift in individuals with autism. Psychologia: An International Journal of Psychology in the Orient, 46, 246-254.

Opie, M., Steele, H., \& Ward, S. (2004). Cognitive outcomes of Sally Ward's early language-based intervention with mothers and babies in longitudinal perspective: Lessons of Head Start revisited. Educational \& Child Psychology, 21(2), $51-66$.

Oviatt, S. L. (1980). The emerging ability to comprehend language: An experimental approach. Child Development, 51, 97-106.

Oviatt, S. L. (1982). Inferring what words mean: Early development in infants' comprehension of common object names. Child Development, 53, 274-277.

Peterson, C. C. (2005). Mind and body: Concepts of human cognition, physiology and false belief in children with autism or typical development. Journal of Autism and Developmental Disorders, 35, 487-497.

Phemister, A. (2005). Reaching kids with Asperger's syndrome. Education Digest, 71(2), 58-63.

Plunkett, K. (1997). Theories of early language acquisition. Trends in Cognitive Sciences, 1, 146-153.

Poulin-Dubois, D., \& Forbes, J. (2006). Word, intention, and action: A two-tiered model of action-word learning. In K. Hirsh-Pasek \& R. M. Golinkoff (Eds.), Action meets word: How children learn words (pp. 262-285). Oxford, UK: Oxford University Press.

Preissler, M. A., \& Carey, S. (2005). The role of inferences about referential intent in word learning: Evidence from autism. Cognition, 97, B13-B23.

Pruden, S. M., Hirsh-Pasek, K., Golinkoff, R. M., \& Hennon, E. A. (2006). The birth of words: Ten-montholds learn words through perceptual salience. Child Development, 77, 266-280.

Ristic, J., Mottron, L., \& Friesen, C. K. (2005). Eyes are special but not for everyone: The case of autism. Cognitive Brain Research, 24, 715-718.

Regier, T., \& Carlson, L. (2002). Spatial language: Perceptual constraints and linguistic variation. In N. Stein, P. Bauer, \& M. Rabinowitz (Eds.), Representation, memory, and development: Essays in honor of Jean Mandler (pp. 199221). Mahwah, NJ: Erlbaum.

Rogers, S. J., \& Pennington, B. F. (1991). A theoretical approach to the deficits in infantile autism. Development and Psychopathology, 3, 806-850.
Rowe, M. L. (2004). A longitudinal investigation of factors related to maternal communicative input and child vocabulary growth in low-income American families. Dissertation Abstracts International: Section B: The Sciences $\mathcal{E}$ Engineering, 64 (8-B), 4087. (UMI No. AAT 3100159)

Ruffman, T. (2000). Nonverbal theory of mind: Is it important, is it implicit, is it simulation, is it relevant to autism? In J. W. Astington (Ed.), Minds in the making: Essays in honor of David R. Olson (pp. 250-266). Malden, MA: Blackwell.

Ruffman, T., Garnham, W., \& Rideout, P. (2001). Social understanding in autism: Eye gaze as a measure of core insights. Journal of Child Psychology and Psychiatry, 42, $1083-1094$.

Rutter, M. (1978). Diagnosis and definitions of childhood autism. Journal of Autism E Childhood Schizophrenia, 8, $139-161$.

Samuelson, L. K., \& Smith, L. B. (1998). Memory and attention make smart word learning: An alternative account of Akhtar, Carpenter, and Tomasello. Child Development, 69, 94-104.

Samuelson, L. K., \& Smith, L. B. (2005). They call it like they see it: Spontaneous naming and attention to shape. Developmental Science, 8, 182-198.

Schnur, J. (2005). Asperger syndrome in children. Journal of the American Academy of Nurse Practitioners, 17(8), 302-308.

Sciutto, M., \& Cantwell, C. (2005). Factors influencing the differential diagnosis of Asperger's disorder and highfunctioning autism. Journal of Developmental E Physical Disabilities, 17, 345-359.

Senju, A., Tojo, Y., \& Yaguchi, K. (2005). Deviant gaze processing in children with autism: An ERP study. Neuropsychologia, 43, 1297-1306.

Senju, A., Yaguchi, K., \& Tojo, Y. (2003). Eye contact does not facilitate detection in children with autism. Cognition, 89, B43-B51.

Shaked, M., \& Yirmiya, N. (2004). Matching procedures in autism research: Evidence from meta-analytic studies. Journal of Autism E Developmental Disorders, 34, 35-40.

Shatz, M. (1994). Theory of mind and the development of social-linguistic intelligence in early childhood. In C. Lewis \& P. Mitchell (Eds.), Children's early understanding of mind (pp. 311-329). Hove, UK: Erlbaum.

Smith, L. B. (1995). Self-organizing processes in learning to learn words: Development is not induction. In C. A. Nelson (Ed.), Basic and applied perspectives on learning, cognition, and development (pp. 1-32). Hillsdale, NJ: Erlbaum.

Smith, L. B. (2000). Learning how to learn words: An associative crane. In R. M. Golinkoff, K. Hirsh-Pasek, L. Bloom, L. B. Smith, A. L. Woodward, N. Akhtar, et al. (Eds.), Becoming a word-learner: A debate on lexical acquisition (pp. 51-80). New York: Oxford University Press.

Steele, S., Joseph, R. M., \& Tager-Flusberg, H. (2003). Brief report: Developmental change in theory of mind abilities in children with autism. Journal of Autism E Developmental Disorders, 33, 461-467. 
Tager-Flusberg, H. (1999). A psychological approach to understanding the social and language impairments in autism. International Review of Psychiatry, 11, 325-334.

Tager-Flusberg, H. (2001). Understanding the language and communicative impairments in autism. In L. M. Glidden (Ed.), International review of research in mental retardation: Autism (pp. 185-205). San Diego, CA: Academic Press.

Tager-Flusberg, H. (2004). Strategies for conducting research on language in autism. Journal of Autism and Developmental Disorders, 34, 75-80.

Tager-Flusberg, H. (2006). Defining language phenotypes in autism. Clinical Neuroscience Research, 6, 219-224.

Tager-Flusberg, H., \& Sullivan, K. (1994). Predicting and explaining behavior: A comparison of autistic, mentally retarded and normal children. Journal of Child Psychology $\mathcal{E}$ Psychiatry $\mathcal{E}$ Allied Disciplines, 35, 1059-1075.

Takata, K., \& Nishikiori, A. (2005). Reconsideration of the role of shape similarity in preschooler's inference about word meanings. Japanese Journal of Psychology, 76, 63-69.

Tan, S. H., \& Schafer, G. (2005). Toddlers' novel word learning: Effects of phonological representation, vocabulary size and parents' ostensive behaviour. First Language, 25, 131-155.

Tomasello, M. (1999). The cultural origins of human cognition. Cambridge, MA: Harvard University Press.

Tomasello, M., \& Barton, M. (1994). Learning words in nonostensive contexts. Developmental Psychology, 30, 639-650.

Walenta, T. M., \& McCabe, P. C. (2004). The utility of the Differential Abilities Scales with specific languageimpaired preschoolers. Journal of Psychoeducational Assessment, 22, 33-46.

Want, S. C., \& Harris, P. L. (2002). How do children ape? Applying concepts from the study of non-human primates to the developmental study of "imitation" in children. Developmental Science, 5, 1-15.

Warreyn, P., Roeyers, H., \& De Groote, I. (2003). Early social communicative behaviours of preschoolers with autism spectrum disorder during interaction with their mothers. Autism, 9, 342-361.

Warreyn, P., Roeyers, H., \& Oelbrandt, T. (2005). What are you looking at? Joint attention and visual perspective taking in young children with autism spectrum disorder. Journal of Developmental and Physical Disabilities, 17, 55-73.

Waxman, S., \& Booth, A. (2003). The origins and evolution of links between word learning and conceptual organization: New evidence from 11-month-olds. Developmental Science, 6, 128-135.
Wellman, H. (1990). The child's theory of mind. Cambridge, MA: MIT Press.

Werker, J. F., Cohen, L., Lloyd, V., Casasola, M., \& Stager, C. (1998). Acquisition of word object associations by 14-month old infants. Developmental Psychology, 34, 1289-1310.

Whiten, A. (2002). Imitation of sequential and hierarchical structure in action: Experimental studies with children and chimpanzees. In K. Dautenhahn \& C. L. Nehaniv (Eds.), Imitation in animals and artifacts (pp. 191-209). Cambridge, MA: MIT Press.

Williamson, R. D. (2005). Cognitive performance of deaf preschool children on the upper preschool level nonverbal cluster of the differential ability scales. Dissertation Abstracts International: Section B: The Sciences and Engineering, 65 (10-B), 5434. (UMI No. 3149731).

Wire, V. (2005). Autistic spectrum disorders and learning foreign languages. Support for Learning, 20, 123-128.

Wittek, A., \& Behrend, D. (2002, April). Children use novel verbs to determine an actors' intention: Evidence from the behavioral reenactment task. Paper presented at the International Conference on Infant Studies, Toronto, Canada.

Woodward, A. (2000). Constraining the problem space in early word learning. In R. M. Golinkoff, K. Hirsh-Pasek, L. Bloom, L. B. Smith, A. L. Woodward, N. Akhtar, et al. (Eds.), Becoming a word-learner: A debate on lexical acquisition (pp. 81 -115). New York: Oxford University Press.

Woodward, A. L., \& Hoyne, K. (1999). Infants' learning about words and sounds in relation to objects. Child Development, 70, 65-78.

Woodward, A. L., Markman, E., \& Fitzsimmons, C. M. (1994). Rapid word learning in 13- and 18-month-olds. Developmental Psychology, 30, 553-556.

Yeargin-Allsopp, M., Rice, C., \& Karapurkar, T. (2003). About 3 in every 1000 U.S. children in large metropolitan areas may have autism or related developmental disorders. Evidence-Based Mental Health, 6(3), 73.

Yeargin-Allsopp, M., Rice, C., Karapurkar, T., Doernberg, N., Boyle, C., \& Murphy, C. (2003). Prevalence of autism in a US metropolitan area. JAMA: Journal of the American Medical Association, 289, 49-56.

Yoshida, H., \& Smith, L. B. (2005). Linguistic cues enhance the learning of perceptual cues. Psychological Science, 16(2), 90-95.

Zwaigenbaum, L., Bryson, S., Rogers, T., Roberts, W., Brian, J., \& Szatmari, P. (2005). Behavioral manifestations of autism in the first year of life. International Journal of Developmental Neuroscience, 23, 143-152. 